\title{
The spread of primary schooling in sub-Saharan Africa: Implications for fertility change
}

Cynthia B. Lloyd

Population Council

Carol E. Kaufman

Population Council

Paul C. Hewett

Population Council

Follow this and additional works at: https://knowledgecommons.popcouncil.org/departments_sbsr-pgy

Part of the Demography, Population, and Ecology Commons

How does access to this work benefit you? Let us know!

\section{Recommended Citation}

Lloyd, Cynthia B., Carol E. Kaufman, and Paul C. Hewett. 1999. "The spread of primary schooling in subSaharan Africa: Implications for fertility change," Policy Research Division Working Paper no. 127. New York: Population Council. Version of record: https://doi.org/10.1111/j.1728-4457.2000.00483.x 


\section{The Spread of Primary Schooling in sub-Saharan Africa: Implications for Fertility Change}

Cynthia B. Lloyd

Carol E. Kaufman

Paul Hewett

1999 No. 127 


\title{
The Spread of Primary Schooling in sub-Saharan Africa: Implications for Fertility Change
}

\author{
Cynthia B. Lloyd \\ Carol E. Kaufman \\ Paul Hewett
}

Cynthia B. Lloyd is Senior Associate and Director of Social Science Research, Carol E. Kaufman is Research Associate, and Paul Hewett is Staff Research Associate, Policy Research Division, Population Council, New York.

The authors thank John Bongaarts, Martin Brockerhoff, Barbara Mensch, Mark Pitt, David Shapiro, and Warren Sanderson for helpful comments on an earlier draft. The authors gratefully acknowledge the generous support of the Rockefeller Foundation under the project, "Interrelationships Between Fertility and Child Investment: New Research Frontiers." Earlier versions of this paper were presented at the International Union for the Scientific Study of Population's Seminar on Reproductive Change in Sub-Saharan Africa, 2-4 November 1998 and at the annual meeting of the Population Association of America, 25-27 March 1999. 


\begin{abstract}
Caldwell hypothesized in 1980 that the onset of the fertility transition would be linked with the achievement of "mass formal schooling." In sub-Saharan Africa, a region where some countries have begun the fertility transition but many have not, the extent of progress toward mass schooling has not yet been assessed. This paper fills a gap in the literature using newly available Demographic and Health Survey data to assess schooling patterns and trends for 17 sub-Saharan countries. As background to that assessment, the paper includes a literature review, an overview of the recent history of African education, and an evaluation of alternative sources of data on education. These data are linked to recent markers of fertility change in order to assess the potential importance of mass schooling for the fertility transition in Africa.

In most of Africa, the promise embodied in early postindependence educational progress whereby the next generation of Africans would be universally exposed to basic levels of formal schooling has yet to be realized. Countries such as Botswana, Ghana, Kenya, Namibia, South Africa, Tanzania, Zambia, and Zimbabwe are the exceptions rather than the rule, and most of these had achieved some form of mass schooling by the early 1980s. Since 1980, growth rates in educational participation and attainment have slowed or halted; in some countries, they have begun to decline. Most of these same countries were in the forefront of the fertility transition in Africa; in Ghana and Tanzania, fertility declines have begun more recently. A systematic empirical analysis of cross-country patterns across all 17 countries supports Caldwell's hypothesis. Within this group, however, we find a few countries beginning to show signs of fertility transition despite limited progress in mass schooling. Côte d'Ivoire and Senegal are notable examples of this new development. In countries where population growth rates remain high and a growing proportion of the population is of school age, the achievement of mass schooling will be increasingly difficult in the future if high fertility persists. Therefore, if fertility declines are to continue, or in some cases begin, they will have to do so in the absence of mass schooling. Instead, fertility may respond to other vehicles of communication, such as the mass media, which will be increasingly pervasive, providing alternative mechanisms for the spread of cultural change.
\end{abstract}

This material may not be reproduced without written permission from the authors. 
Caldwell (1980) hypothesized that the onset of the fertility transition would be linked with the achievement of "mass formal schooling," by which he meant nearuniversal enrollment of children in primary or basic schooling. In sub-Saharan Africa, a region in which the fertility transition has begun in some countries but not in others, this hypothesis remains untested. In all of these countries, formal schooling is a foreign import, imposed in a variety of different ways over the last century by colonial regimes and foreign churches. In more recent years, as former colonies have gained their independence, most governments have made significant budgetary commitments to education, and educational systems have been revised and reformed to serve the goals of independent states. Today, the educational systems arrayed across the African continent show enormous variation, with many retaining strong links to their colonial roots. Some countries have achieved near-universal enrollment at the primary-school level, but most have not. In some, the gender gap in enrollment rates remains large despite significant progress, but in most, substantial progress has been made to close that gap. Furthermore, recent setbacks in enrollment in response to rising school costs, brought on in many cases by governmental responses to economic reversals and to structural adjustment conditions, add complexity to considerations of the fertility implications of educational transitions.

The primary focus of this paper is on schooling patterns and trends in sub-Saharan Africa. Despite constant references in the demographic literature to the importance of education, considerable ignorance persists about actual enrollment trends or schooling conditions and about the state policies that lie behind them. The most widely used statistical indicator of educational participation produced by the United Nations Educational, Scientific, and Cultural Organization (UNESCO) — the gross enrollment ratio-is fundamentally flawed and misleading. To measure the extent of participation in school, consistent data from a census or a survey are necessary for estimating the proportion of a particular age cohort that has ever been to school or that has attained a certain level of schooling. Meaningful rates of educational participation that can be compared across countries and over time cannot be derived, as are gross enrollment ratios, from enrollment reports provided by schools and district offices. In a world of shrinking budgets and rapidly growing school-aged populations, educational institutions have substantial incentive to inflate their numbers to protect their share of government resources. Unfortunately, despite considerable investment by the United Nations (UN) in training for 
African censuses conducted in the 1980s and 1990s, little of the extensive census data collected has become accessible for further analysis within the UN system or even for country nationals' use. ${ }^{1}$ A substantial investment over the last two rounds of the Demographic and Health Survey (DHS) Program in the collection of basic data on education in the household surveys now provides an opportunity to study educational patterns and trends on a fully comparable basis for the first time. These data also can be compared with UNESCO enrollment data and, for some countries, with published census data, thus providing greater insight into educational patterns and trends and into issues of data quality. The assessment of recent schooling patterns and postindependence trends based on DHS data is, therefore, the main contribution of this paper.

The motivation for undertaking this assessment is the authors' interest in contributing to the literature on African transitions, both demographic and otherwise. State educational policies, which affect not only the accessibility, price, and quality of formal schooling but also the extent to which participation is voluntary, represent a critical dimension of the economics of family building in all societies as well as a primary means of socialization by the state. In Africa, where many fertility transitions have not yet begun or are just beginning, the spread of education has not yet been assessed in any comprehensive way.

The paper reviews the literature concerning the links between education-particularly the mass schooling of the young - and fertility in developing countries, with a particular emphasis on recent African experience. The evolution of formal schooling in Africa is described, beginning with its colonial roots and continuing with policies and programs of the state in the postindependence era. After a brief discussion of the advantages and disadvantages of different sources of data on school enrollment and attainment, empirical findings on progress toward mass schooling are presented. Although data from all countries in the region cannot be presented, a sample of 17 countries is included with appropriate data on education from western, eastern, and southern Africa, representing different colonial traditions and postindependence educational policies (see Table 1). ${ }^{2}$ In operationalizing the concept of mass schooling, various dimensions of formal education are considered, including its depth, as measured by years of attainment and primary completion; its degree of gender equity; its spread from urban to rural areas; and 


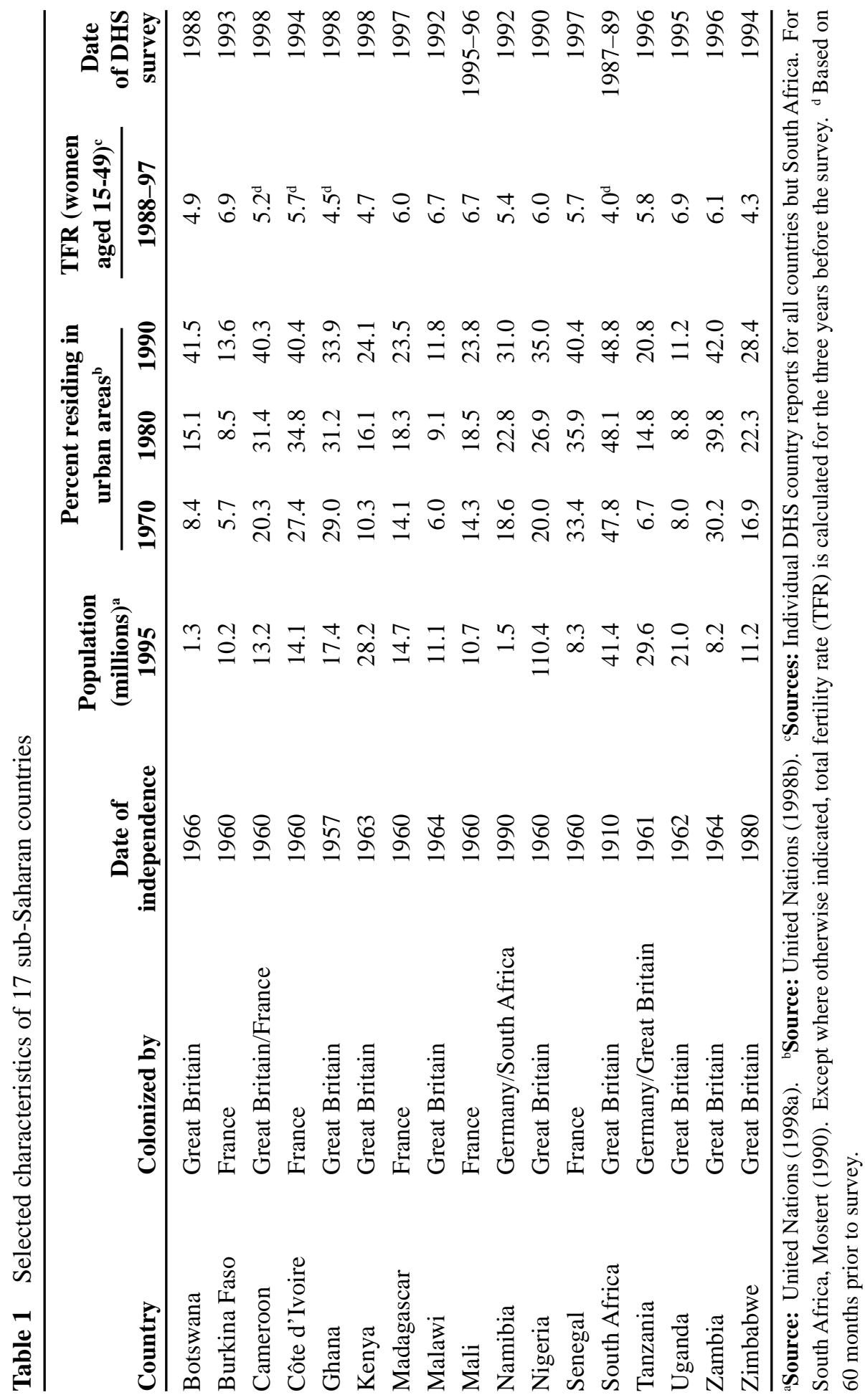


its pace of change. Finally, the cross-country relationship between levels of schooling attained and recent markers of the fertility transition are explored. The paper concludes with some final thoughts on Caldwell's hypothesis in light of recent African experience.

\section{PAST TheORY AND EVIDENCE}

Almost two decades have passed since the publication of Caldwell's (1980) article on "Mass education as a determinant of the timing of fertility decline." The links he hypothesized between mass schooling and fertility were based largely on the historical experience of the West. At that time, he faulted much of the literature on education and fertility in developing countries for having neglected the more immediate impact of children's schooling on the reproductive decisionmaking of parents, and for having concentrated instead on the impact of parents' own education on their subsequent fertility. Even though the period since his article was written has encompassed the start of many fertility declines throughout the world, his same criticism could be leveled at the literature even more aptly today. In a review of the state of knowledge on education and fertility by the Committee on Population of the National Academy of Sciences (Bledsoe et al. 1999), not a single article addresses this question. Before reviewing what is known about the relationship between education and fertility in Africa, Caldwell's hypothesis is revisited here, setting it in the context of other relevant literature on the demographic transition.

\section{CALDWELL'S HYPOTHESIS REVISITED}

Caldwell (1980) listed five mechanisms through which the arrival of mass schooling affects the family economy: (1) by reducing the time that children are able and/or willing to work on behalf of the family either inside or outside the home; (2) by raising the direct costs of children, not only because of the many costs directly or indirectly associated with school attendance but also because of the additional demands on resources placed on parents by children who have gained a new authority in the home; (3) by creating social norms about childhood as a phase of dependency; (4) by speeding up cultural change and creating new cultures; and (5) in the case of the less developed countries, by propagating Western middle-class values. Caldwell cited Coale (1969), who defined mass schooling as the point at which 90 percent of children of primary- 
school age attend school, and he emphasized that the "most potent force for change is the breadth of education (the proportion of the community receiving some schooling) rather than the depth (the average duration of schooling among those who have attended school)" (Caldwell 1980: 249).

Although mechanisms 1 and 2 are directly related to the economic changes that would ensue in a particular family if a child in that family were to attend school, mechanisms 3, 4, and 5 appear potentially broader in their implications. Indeed, farther on in his article, Caldwell posits that, at the point where mass schooling has its effects in launching fertility decline, those effects are or will be universal, affecting all parents, regardless of their educational level, simultaneously. Thus, although he saw the effects of mass schooling on parental reproductive behavior as working primarily through the cumulative changes in the economics of many individual families, apparently he also saw that externalities could arise from mass schooling in such a way that even those parents whose children were not yet in school would change their reproductive behavior. Indeed, for clarity we might respecify mechanisms 1 and 2 as pertaining directly to changes in the family economy and mechanisms 3,4 , and 5 as pertaining to some of the social externalities of schooling.

Caldwell's hypothesis was based on a review of the experience of industrialized countries with the onset of fertility decline and the timing of the arrival of mass schooling. He observed that the availability of schools and the adoption of compulsory schooling laws were clearly not sufficient by themselves. Rather, he identified the systematic enforcement of compulsory schooling laws as critical. Although recognizing that the beginning of the fertility decline in France dates prior to the enforcement of compulsory schooling laws, Caldwell linked the acceleration of the fertility decline in France that occurred in the late nineteenth century to the achievement of effective compulsory schooling that took place during that same period. In discussing the role of the state in the English fertility transition, Johansson (1991) reiterated this key dimension of schooling. She identified the enforcement of compulsory schooling along with the raising of schoolleaving ages as the most effective state policy in enforcing "altruistic parenting" (p. 400) and effecting fertility decline.

Caldwell's hypothesis, particularly as it relates to mechanisms 1 and 2, which are directly linked to the economics of the family, is entirely consistent with Becker's (1991) 
predictions of rapid fertility decline in response to rises in the price of children as parents trade off quality against quantity. Although Becker did not use the enforcement of compulsory school laws as an example of the rising costs of children in his analysis, it could have been a particularly good one. With the enforcement of compulsory school laws, the price of each child rises and, at the same time, parents are no longer free to discriminate between children according to sex or birth order, at least through the basic years of schooling. This situation implies a shift in demand away from quantity to quality, which leads to further increases in the price of children as parents are forced to incur the additional out-of-pocket expenses of sending their children to school and the opportunity costs of losing their children's time for domestic work or in support of family enterprises. By identifying the ways in which power shifts from the older to the younger generation as parents reduce their demand for quantity and increase their demand for quality, Caldwell put sociological flesh on the bare bones of economic theory by illustrating some of the processes through which the shift from quantity to quality may occur.

Caldwell's hypothesis, particularly that part concerning mechanisms 3 and 4 as they relate to the social externalities of schooling, is surprisingly consistent in its implications with some of Watkins's (1991) theories about the social forces underlying the demographic integration of Europe during the years 1870 to 1960. In her book, From Provinces into Nations: Demographic Integration in Western Europe, 1870-1960, Watkins makes a compelling case for the decline in linguistic diversity, the rise in national markets, and the expansion of state power and control as key factors in the shift to greater national demographic homogeneity as fertility decline spread from just a few pockets within each country to encompass, ultimately, the whole of each European nation. Indeed, Watkins identifies schooling as the most important aspect of nation building, particularly because of the enforcement of a national language (or languages, in countries having more than one) as the medium of instruction in schools. She focuses primarily on the role of the school in bringing diverse parts of the state together through a common language. The imposition of a common curriculum, often taught by teachers from different parts of a country, might also be considered an important aspect of nation building. Watkins also confirms Caldwell's interpretation of the French data, dating the decline in other languages and dialects in France to the reforms of Jules Ferry, Minister 
of Public Instruction under the Third Republic, which introduced free and compulsory primary schooling in French in 1875 . Beyond this date, fertility decline accelerated in France as traditionally nonfrancophone areas of the country joined in the decline that had emerged earlier in francophone areas. Whereas Watkins emphasizes the role of linguistic homogeneity and market integration in promoting social interaction or diffusion, which she sees as the main determinant of fertility decline, Caldwell emphasizes the role of schools in changing norms about childrearing, both through their effects on the economics of individual families and through their more global effects on the national culture. These perspectives can be fully reconciled if changing norms about childrearing are, in fact, being diffused as a result of nearly universal school attendance, greater linguistic homogeneity, and the growing role of the state in setting a uniform national curriculum.

The fifth mechanism through which Caldwell hypothesized that mass schooling might operate in developing countries was through the spread of Western middle-class values. Given the limits of technology during the time at which he was writing, he probably saw formal schooling as the primary vehicle through which such values could be spread. Today, with radio and television nearly universally accessible, new and powerful forces of globalization are at work that can both reinforce the effects of mass schooling and possibly bypass them. Bongaarts and Watkins's (1996) analysis of the pace of change in contemporary fertility transitions, primarily in Asia and Latin America, suggests that once fertility decline begins in a few countries within a region, it spreads to others, even to those where socioeconomic conditions are less favorable, suggesting a process of cross-border diffusion.

In his predictions for the developing world, Caldwell (1980) added a few caveats. First, he conjectured that demographic change would be unlikely if the achievement of mass schooling is confined largely to boys. Second, he played it safe by adding that, although the first generation of mass schooling should be sufficient to trigger the onset of fertility decline, if it does not, the second generation of mass schooling should guarantee it. He mentioned nothing about the role of schools in developing a common national language, however, a key issue that Watkins identifies in the historical record. The issue of a common language is of particular concern in Africa, where linguists 
identify more than 1,250 languages currently in use, only nine of which are spoken as a first or second language by as many as ten million people each (World Bank 1988).

Since Caldwell first elaborated his mass-schooling hypothesis, much change has occurred in the African subcontinent. A few countries are clearly in the process of a rapid fertility transition, and there are hints that the process has begun in a handful of other countries (Cohen 1998; Kirk and Pillet 1998). Formal schooling has been a presence on the subcontinent since colonial times and has exhibited rapid spread in the years since independence in response to rising national aspirations as well as to donor pressures. In light of the historical experience of the West, however, the assumption that mass schooling can be achieved in Africa in the absence of the enforcement of widespread compulsory schooling laws may appear unreasonable. Ninety percent school participation in a setting where every child attends school for some required number of years would differ greatly from 90 percent school participation in an environment where, for the majority, that rate reflects nothing more than a few years of sporadic attendance. Furthermore, economic decline and the resulting structural adjustment policies have slowed or reversed some earlier gains. In what follows, we briefly review recent research findings that may shed some light on the schooling-fertility relationship in subSaharan Africa.

\section{EMPIRICAL EVIDENCE}

In our review of the empirical evidence, only three studies were found that explore statistically the direct effects of children's schooling at the community level on fertility or contraceptive use and only one that is specifically focused on Africa. ${ }^{3}$ Casterline (1985) used rural data from the 1980 World Fertility Survey (WFS) for Egypt to test whether children's access to schools at the village level as well as the primary attendance ratio for girls and boys might affect parents' educational aspirations for their children and their contraceptive use. He found that the desired number of years of school for boys was negatively affected by distance to secondary school and that the desired number of years of school for girls was negatively affected by distance to primary school and positively affected by primary enrollment in the village. He found, too, that current contraceptive use was affected positively by the village primary-school enrollment rate 
for girls but negatively by the primary-school enrollment rate for boys. More recently, Guilkey and Jayne (1997), analyzing data from the 1989 Zimbabwe DHS survey, show that the number of educational opportunities in the community (the measurement of which was not defined) had a positive and statistically significant effect on contraceptive use. Most recently, Axinn and Barber (1999), using rich contemporary and retrospective data on 171 communities in Nepal, find that living near a school significantly increases a woman's chance of adopting a permanent contraceptive, even controlling for the proximity of a school during a woman's childhood - a variable with its own independent effect on contraceptive use.

Studies of the cross-sectional statistical relationships between women's schooling and fertility abound, however. A few recent studies lend some empirical support to the notion that the community context, in terms of levels of schooling, can contribute to strengthening the relationship between parents' schooling and their fertility. Van de Walle and Foster (1990: 16) pose the question of whether "Africa is on schedule" in terms of fertility decline. Using an international cross-section of developing countries, they find that the higher the female primary-school enrollment ratio in 1965, the more rapidly fertility declined in the subsequent two decades. The effect was much weaker for Africa, however. A recent update of Jejeebhoy's (1995) extensive comparative analysis of results from WFS and DHS data by Diamond et al. (1999) attempts to explain variations across countries in the effects on fertility of just a few years of schooling. In some settings, women with a few years of schooling seem to have higher fertility than those with none, whereas in other settings, the opposite is true. They found that in countries with higher income per capita and higher levels of female literacy, a few years of schooling had a depressing effect on fertility. With an exclusive focus on sub-Saharan African results, Ainsworth et al. (1996) also find that those countries in which the women sampled had the highest mean number of years of schooling displayed the strongest negative statistical relationships between number of years of education and cumulative fertility.

Many recent country case studies also call attention to the importance of parents' education (often female education), in particular, of shifts in its distribution over time, for explaining fertility patterns and trends. Shapiro (1996: 90) points to increases in the educational attainment of the female population in Kinshasa, Congo (formerly Zaire) as 
the "single most important factor" contributing to fertility decline. Dow et al. (1994) identifies the rising educational aspirations of increasingly educated rural fathers in Kenya, along with rising educational costs, as a major factor in the reduction of family size desires. Thomas and Maluccio (1996: 216) speak of the "powerful impact" of education on contraceptive use and fertility in Zimbabwe, especially, in the case of fertility, among younger and urban women. Thomas (1998) found similar results in South Africa. Rutenberg and Diamond (1993) attribute roughly only a third of the decline of nearly one birth per woman in Botswana in the 1980s to the shifting composition of the population by age, education, and residence. Nonetheless, they note that the government responded to a major drought in rural areas in the early 1980s with supplementary feeding programs in the schools, a factor that may have boosted children's enrollment and led to changes in the costs of childrearing, a potential explanation for the part of the fertility decline not explored further in their study. Furthermore, Rutenberg and Diamond do not mention that public-sector primary-school fees were abolished in 1980, despite difficult economic conditions (Working Group on Factors Affecting Contraceptive Use 1993). Pison et al. (1995), using time-series and cross-district (departments) analysis for Senegal, point to rising female education as a factor in delays in the age of marriage and in the decline in fertility rates among those women younger than 30 between the late 1970s and the early 1990s. Strikingly, none of these authors mentioned the more contemporary effects of mass schooling on fertility.

In recent literature on African fertility transitions, Kenya has received special attention. Researchers have been more likely to identify mass schooling in Kenya than elsewhere as a causal factor in the acceleration of fertility decline. Kelley and Nobbe (1990) point, in particular, to the rising costs of schooling as a key factor in the Kenyan transition. The effects of rising costs should be particularly powerful in a context where most children already attend school and where educational aspirations are high. Robinson (1992: 456) notes the tremendous commitment of the Kenyan government to education, the enormous investment in infrastructure, particularly in secondary schools, as well as the system of fee-based cost sharing as factors with "direct relevance to the fertility control program." Brass and Jolley (1993) mention as key factors explaining the fertility decline that mass literacy has been achieved for those younger than 40; that parents 
share costs of education with the government by helping to build and maintain schools, in addition to buying books and supplies; and that primary-school attendance has been mandatory since 1978. None of these three in-depth treatments of the Kenyan transition substantiates these assertions empirically, however.

The Working Group on Factors Affecting Contraceptive Use (1993), part of a recent National Academy of Science's (NAS) panel on Africa, speculates on the prospects for a quantity-quality tradeoff leading to a fertility decline in the context of dramatic shifts in financing of education since the mid-1980s. In many countries, parental costs of children's schooling have risen substantially as governments have required them to pay a greater portion of the costs of education, but, at the same time, school quality has been deteriorating. These changes followed an impressive period of growth from 1960-80, two decades during which new African governments outperformed most other regions in growth in educational expenditure and enrollment (Schultz 1987). ${ }^{4}$ The Working Group's predictions are carefully qualified. They regard the prospects for a quantity-quality transition in the region as "decidedly mixed" (p. 76). The Group feels it unlikely that "African parents will continue to make sacrifices to invest in human capital if the payoff to that investment is in doubt" (p. 77). In a context of rising prices and declining job prospects, decisions about education hinge on parental assessments of the value of schooling for their children in relation to its costs. While the Working Group notes evidence from focus-group discussions in Niger and Nigeria that parents are increasingly aware of the rising costs of rearing children and that they mention such costs as a principal disadvantage of having large families, the Group also points out that enrollments have been declining in some countries in response to these changes. They conclude that "the more responsive the demand is for education with respect to price, the less likely are the prospects for a quantity-quality tradeoff' (p. 81).

All of these studies are disadvantaged by the nature of their data. A theory about the onset of fertility decline cannot be tested by looking at cross-sectional correlations at a single point in time or at the experience of any one country over time. Comparisons across countries over time are required. Educational policy that affects the accessibility, price, and quality of schooling as well as the degree of enforcement of compulsory schooling operates at the level of the state. Indeed, if educational systems at the state 
level are most salient in their implications for demographic change, then none of the evidence reviewed up to this point can be used to prove or disprove the demographic importance of mass schooling (see Amin and Lloyd [1998] for an analogous point about gender systems). As Mason (1997) points out, the impact of changes in opportunity structures at the level of the state (she uses the example of women's opportunities or gender systems) can only be played out through the observation of successive cohorts. Furthermore, the experiences of one country must be set against the experiences of others in order to observe commonalties and differences. Before we turn to the trends in education since independence, some background on the colonial legacy as it has affected the education sector and a comparison of the evolution of state educational policies since independence are useful.

\section{THE Evolution OF FORMAL SCHOOLING IN AFRICA}

Current educational systems in sub-Saharan Africa have been forged from inherited colonial structures and an array of postindependence strategies to expand and improve educational opportunities. Although colonial approaches to education varied considerably across the region, they all offered schooling only to a small minority of the African population. Governments of the new states of Africa were faced with the monumental task of putting into place a comprehensive systems of schools, teachers, and books where none existed. The diverse approaches to this task were closely tied to colonial experience.

\section{Colonial Educational Systems}

Educational systems in colonial Africa mirrored those of the metropole (typically, the colonial power's capital city), and, by the end of the colonial period, most operated dual systems, one for (white) colonials and another for Africans. The children of colonial Europeans typically began their education locally with a curriculum that was often wholly imported from abroad. They completed tertiary, and sometimes even secondary school in Europe. In contrast, the authority and administration of education for Africans proceeded along lines consistent with the aims of the particular colonial presence. The French administration's policy toward Africans was one of assimilation; Afri- 
cans, through proper training, could be inducted into the French way of life. The French held no pretense of offering this training universally, opting instead for "civilizing" a select few Africans with the ultimate goal of granting them French citizenship. The Portuguese also professed a policy of assimilation for Africans under their jurisdiction, but in practice the implementation of their approach was one of remote association. Plagued with political and economic difficulties in the colonies and in Portugal, the education of Africans was generally ignored in Portuguese territories (Duffy 1961 and 1970). The Belgian colonial presence was one of the harshest; Belgians overtly sought to maintain their supremacy and denied virtually all Africans any form of meaningful educational or economic advancement. The mass of Africans were to be used, for their own good and the good of the crown, as inexpensive labor (Scanlon 1964). Finally, the British colonial approach to the "Native question" was one of segregation and paternalism. ${ }^{5}$ The British never accepted that Africans could become equal, or that they would be suitable for the responsibilities and privileges of British citizenship. However, Africans could be trained to fulfill some lower-level clerkship or administrative responsibilities, and a few could be entrusted with the implementation of British policies. The British conceded that they had a responsibility to "uplift" the African from what they perceived as a low level of civilization, but any notion of equality to Europeans was summarily dismissed by most (Dubow 1987). The British and the Belgians viewed Africans collectively in racial terms, though the British were much more tolerant of local customs and autonomy than was any other colonial power. The French and Portuguese, in contrast, emphasized individual qualities of a select few at the cost of neglecting the majority (Uchendu 1979).

In each of the colonial "Native" policies, the role of missionaries and the degree of centralized control exerted by the colonial regime largely determined the depth, spread, and content of African education prior to independence. ${ }^{6}$ In French West Africa, for example, all missionary schools were required to adhere to a common French curriculum by the turn of the twentieth century. French colonial education focused on training Africans to become French: Subjects were taught in French, emphasized French culture, and ideally, training was equivalent to that in French schools. For the exceptional, education continued through the tertiary level at the metropole. Those who received ad- 
vanced training were a select minority, chosen with great care by the colonials. Others not permitted to matriculate in academically oriented schools were trained in basic hygiene, agricultural sciences, and vocational crafts, the skills considered by the French to be the most useful for the majority, an unpopular policy with parents, who thought education should allow for social and economic advancement (Yansané 1985). The Portuguese maintained a similar doctrine, although without an enforced centralization of policy. Instruction promoted African assimilation, but little was done to provide widespread education. As with the French, the Portuguese offered academic training to a select few in urban areas. Only a small portion of other children had the chance to attend basic primary schools offering a second-tier curriculum, one nonetheless designed to promote Portuguese language and civilization. The government operated few schools outside urban areas and relied upon missionaries to teach the "uncivilized" sector of the African population as they saw fit (Duffy 1961).

The British colonial system of education contrasts sharply with the French. Missionary schools were the vehicle of education in the British colonies; the colonial government had few schools of their own. The colonial government provided educational subsidies to voluntary organizations, but did little to centralize practices or impose universal standards (Cameron 1970). Although the autonomy accorded missionaries allowed for flexibility and accommodation to local environments, it also led to a great deal of experimentation and wide variation in curricular content. Depending on the school's religious denomination and order, subjects of instruction ranged from moral values or biblical studies to liberal arts to vocational crafts. Also, in direct contrast to the French and congruent with the British philosophy of upliftment, the British encouraged some minimal level of education for all Africans (Cameron 1970). The intent was to provide basic education to Africans to make them productive members of the colony, and to provide extra training for the few who would then take on low-level administrative positions (Uchendu 1979).

The Belgian system of education was systematic and explicit. Missionary schools functioned as authorized government schools until 1953, and thereafter continued to work in an official capacity. Education was utilitarian and centralized, designed to provide a minimal level of schooling to all Africans to make them useful as cheap labor for 
industry. Few opportunities existed for Africans to attain a secondary education, and virtually none for education beyond that level. Furthermore, the missionaries of the Belgian Congo were more homogenous than were those in the British colonies or even in the French territories. Missionaries were predominantly Roman Catholic, and most were from rural, conservative orders in Belgium that did not stress intellectual development (Yates 1982). Unlike the French and British systems, which provided higher training for an elite group, the Belgian colonial system saw no use in providing Africans with anything more than a basic education (Scanlon 1964).

The various forms of colonial education for "Natives" was tightly bound to the ideology of each colonial power, informed by the structure of rule imposed by Europeans, and ultimately designed to serve the purposes of the colonials who lived there. Language policies for entry-level primary school are a good example of this point. In the former British colonies, 13 out of 15 use one or more African language as the medium of instruction, whereas in 11 out of 15 former French colonies, French is used as the medium of instruction; this sort of policy applies to all three of the former Portuguese colonies as well (World Bank 1988). No country in colonial Africa provided universal schooling; however, those colonies that had strong settler economies, primarily in eastern and southern Africa, provided schooling to more native children than did colonies in other areas. Europeans living in settler colonies simply required greater numbers of educated employees. In those colonies with predominately extractive economies (agriculture or mining), educated workers were not critical to successful operations, and therefore, schooling was not a priority.

\section{Postindependence Trends in Education}

At independence, each new African state had the daunting task of transforming dual and largely segregated educational structures into one unified system to which access was possible — if not fully realized in the short run—for all citizens. ${ }^{7}$ Another, and no less important task, was to establish a uniform national curriculum that was consistent with the development and social objectives of the independent state (Marah 1989). The issue of which language or languages to choose as a medium of instruction was a further challenge. The pedagogical advantages of early learning in the mother 
tongue had to be weighed against the need to create literacy in a common national language in the context of a continent that was and remains largely fractionalized along ethnolinguistic lines. ${ }^{8}$ Education was seen as a means both for rapid economic development and for the dissemination of a unified set of national civic values. ${ }^{9}$ The achievement of these goals required a dismantling of the de jure and de facto barriers to education, while also generating the levels of investment and financing necessary to support the expansion of the education sector.

The challenge was to accomplish these tasks while using limited resources efficiently. In most cases, the dramatic growth of investment in education in the early postindependence period brought virtually no concomitant attempt to redefine the basic assumptions of the educational system or to alter drastically the framework of the provision of education inherited from the former colonial regimes. ${ }^{10}$ Instead, the African states co-opted existing systems and modified only those aspects that were clearly incongruent with their objectives. The educational system of the newly independent state thus represented an extension, rather than a replacement, of existing modalities.

In the former French colonial states where educational systems had focused primarily on the assimilation of a limited number of African elites through schooling controlled by the metropole, an already centralized system was transferred to African control. The educational system was expanded to the general population and loyalty to France was replaced by nationalism. Nonetheless, for most countries, close relations with France continued, and a strong French influence remained in the structure and content of education.

In the former British colonial states, which had provided basic education to more Africans than had the French system, the newly independent states took on the ambitious task of centralizing, integrating, and standardizing the diverse field of educational provision, creating a system that would focus on national rather than local or particular interests and goals. A few countries pursued a socialist approach, including Tanzania and Zimbabwe. In these countries, the curriculum was adapted to teach socialist values and doctrines. Although different in style from other countries, those advocating a socialist approach focused on many of the same goals as did the others, including expanding access to education to all citizens, granting them equality of opportunity, and recognizing the importance of education for national development. 
Regardless of postindependence approaches to development, the importance accorded to education in national development plans led to a dramatic increase in educational expenditure and a tremendous expansion of the educational infrastructure. These investments were facilitated by strong economic growth rates in the late 1960s and 1970s (Kinyanjui 1993; World Bank 1988). For instance, total public expenditure on education in constant US dollars grew by roughly 7 percent a year between 1970 and 1980 on average across sub-Saharan Africa, with similar average rates of growth in the former British and French colonies, well above the rates required to keep pace with the growth in school-age populations (Donors to African Education 1994). Indeed, growth of educational expenditure exceeded growth in gross national product (GNP) over the decade of the 1970s, resulting in a rising percentage of GNP devoted to educational expenditure. By 1980, the average proportion of GNP devoted to educational expenditure had grown from 3.2 to 4.2 percent, with similar growth in former British and former French colonies (see Table 2). Particular countries, including Botswana, Côte d'Ivoire, and Kenya, allocated sizably greater proportions of their GNPs to educational expenditure than average during this period (Donors to African Education 1994). ${ }^{11}$ Despite average declines in the percentage of the overall education budget allocated to primary schooling during the 1970s, all regions showed small increases in per-pupil expenditures at the primary level, suggesting slight improvements in educational quality. ${ }^{12}$

The economic and political conditions in the 1980s, however, sharply curtailed and often ended the impressive educational gains of the prior two decades. African countries were particularly hard hit by increased world prices for oil, decreased export prices, and higher external debt (Hodd 1989; World Bank 1988). Additionally, most countries underwent structural adjustment programs that resulted in cutbacks in social-sector spending, including educational expenditures (Reimers 1994). ${ }^{13}$ This retraction of national investment in education is reflected in declines in the growth rate of educational expenditures in constant dollars from 6.2 on average from 1970-80 to 2.1 from 1980-90 (Donors to African Education 1994). The decline in average growth rates in educational expenditure was even more dramatic in the former French colonies $(6.7$ percent per annum to 0.5 percent per annum) than in the former British colonies (6.5 percent per annum to 2.2 per annum). These trends are reflected in the percentage of GNP devoted to educational expenditure; in the former French colonies, the average declined from 4.3 
Table 2 Trends in educational investment indicators for sub-Saharan Africa, by former colonial status

\begin{tabular}{|c|c|c|c|}
\hline Expenditure & $\begin{array}{l}\text { Former British } \\
\text { colonies }(\mathbf{N})\end{array}$ & $\begin{array}{c}\text { Former French } \\
\text { colonies }(\mathbf{N})\end{array}$ & All countries $(\mathbf{N})$ \\
\hline \multicolumn{4}{|c|}{$\begin{array}{l}\text { Total public expenditure on } \\
\text { education as percentage of GNP }\end{array}$} \\
\hline 1970 & 3.7 (15) & 3.3 (13) & 3.2 (34) \\
\hline 1980 & $4.5 \quad(15)$ & $4.3 \quad(13)$ & $4.2 \quad(36)$ \\
\hline 1990 & $4.8 \quad(13)$ & $3.6 \quad(15)$ & $4.1 \quad(36)$ \\
\hline \multicolumn{4}{|c|}{$\begin{array}{l}\text { Percent of recurrent public } \\
\text { expenditures on education } \\
\text { allocated to primary schooling }\end{array}$} \\
\hline 1970 & $47 \quad(13)$ & $51 \quad(10)$ & $49 \quad(26)$ \\
\hline 1980 & $44 \quad(15)$ & $43 \quad(14)$ & $44 \quad(33)$ \\
\hline 1990 & 37 (12) & $45 \quad(13)$ & $45 \quad(32)$ \\
\hline \multicolumn{4}{|c|}{$\begin{array}{l}\text { Current public expenditure } \\
\text { for primary-school student } \\
\text { (constant } 1990 \text { US\$) }\end{array}$} \\
\hline 1970 & $49 \quad(10)$ & 102 & $71 \quad(22)$ \\
\hline 1980 & $58 \quad(14)$ & 109 (12) & $74 \quad(31)$ \\
\hline 1990 & $60 \quad(12)$ & $96 \quad(11)$ & 76 (29) \\
\hline
\end{tabular}

Note: The following small island states are not included in the averages: Comoros, Cape Verde, Mauritius, São Tomé and Principe, and Seychelles. South Africa is also excluded because data are not strictly comparable.

Source: Donors to African Education (1994).

percent in 1980 to 3.6 percent in 1990, whereas in the former British colonies the average percentage rose slightly from 4.5 percent to 4.8 percent (as shown in Table 2 ). While per-pupil expenditures on primary schooling were maintained at roughly their 1980 level in the former British colonies, per-pupil expenditures declined on average in the former French colonies, suggesting a decline in resources per student.

In addition to economic decline in the region, for many other countries in Africa during the 1970s and 1980 (for example, Angola, Ethiopia, Liberia, Mozambique, Nigeria, Sierra Leone, Somalia, and Sudan), political instability and internal conflict resulted 
in a marked decline in education and in its infrastructure, including a reduction in the depth and breadth of educational development (Kinyanjui 1993). For example, nine years after the Amin coup in 1971, Uganda had the lowest per-pupil spending levels among all the countries, and this pattern continued until 1990 (Donors to African Education 1994). In Nigeria, political instability led to a continuous decline in educational expenditures of 15.7 percent per year during the 1980s (Donors to African Education 1994). The impact of instability and conflict on education is no less relevant in the 1990s for countries such as Burundi, Congo, and Rwanda.

In the 1990s, qualitative evaluations of the educational situation in the region describe a thinning of the provision of schooling and the inability of countries to maintain even current levels of educational achievement, given lagging growth in investment and accelerating growth in the size of school-age cohorts (Kinyanjui 1993; Nieuwenhuis 1996). Table 3 presents three indicators of the level and focus of investment in education for the early 1990s for the subset of sub-Saharan countries selected for this analysis. They include the total public expenditure for education as a percentage of GNP, current expenditures per primary-school student, and the percentage of recurrent public expenditure for the primary-school level.

A tremendous range is found across Africa in 1990 in the share of national GNP devoted to public education, an indicator that can be used to rank countries according to their overall level of commitment to educational investment. Although poor countries spend less overall on education, lower incomes per se should not be presumed to be a factor in reducing the proportion of that income allocated to education. The countries committing more than 5 percent of GNP to education, an impressive commitment, include Botswana, Côte d'Ivoire, Kenya, Mozambique, Namibia, South Africa, Tanzania, and Zimbabwe. How this level of financial commitment translates into opportunities for basic education at the primary level depends on the underlying level of development of the country as reflected in its GNP, the proportion of the total education budget devoted to schooling at the primary level, the number of students enrolled in primary school, and teachers' salaries (the major component of recurrent educational expenditures in the primary sector). Countries that allocate more than 50 percent of their overall education budget to primary schooling include Angola, Cameroon, Congo, Ethiopia, Kenya, and 
Table 3 Recent national expenditure on education among selected sub-Saharan countries, 1990

\begin{tabular}{|c|c|c|c|}
\hline $\begin{array}{l}\text { Colonial } \\
\text { history } \\
\text { and country }\end{array}$ & $\begin{array}{l}\text { tal public } \\
\text { enditure for } \\
\text { lucation as } \\
\text { ntage of GNP }\end{array}$ & $\begin{array}{l}\text { Percentage of public } \\
\text { recurrent expenditure } \\
\text { for education allocated } \\
\text { to primary schooling }\end{array}$ & $\begin{array}{c}\text { Public current } \\
\text { expenditure } \\
\text { per primary- } \\
\text { school student } \\
\text { (constant } 1990 \text { US\$) }\end{array}$ \\
\hline \multicolumn{4}{|l|}{ British } \\
\hline Botswana & 8.4 & 31 & 219 \\
\hline Ghana & 3.3 & 29 & 21 \\
\hline Kenya & 6.8 & 57 & 46 \\
\hline Malawi & 3.4 & 42 & 17 \\
\hline Nigeria & 1.7 & $17^{\mathrm{a}}$ & $18^{\mathrm{a}}$ \\
\hline Tanzania & 5.8 & 42 & 12 \\
\hline Uganda & 2.9 & 20 & 5 \\
\hline Zambia & 2.9 & 32 & 16 \\
\hline Zimbabwe & 11.4 & 54 & 126 \\
\hline \multicolumn{4}{|l|}{ French } \\
\hline Burkina Faso & 2.3 & 42 & 61 \\
\hline Cameroon & 3.4 & 70 & 90 \\
\hline Côte d'Ivoire & 6.3 & $40^{\mathrm{b}}$ & $193^{\mathrm{b}}$ \\
\hline Madagascar & 1.5 & 50 & 17 \\
\hline Mali & 3.2 & 46 & 107 \\
\hline Senegal & 3.7 & 39 & 116 \\
\hline \multicolumn{4}{|l|}{ Other } \\
\hline Angola & na & 96 & 261 \\
\hline Congo (former Zaire) & 0.9 & 55 & 9 \\
\hline Ethiopia & 4.9 & 54 & 51 \\
\hline Mozambique & 6.3 & 50 & 20 \\
\hline Namibia & 8.0 & 21 & na \\
\hline South Africa & 5.5 & $72^{\mathrm{c}}$ & 1,782 \\
\hline
\end{tabular}

na=Not available. ${ }^{\mathrm{a}} 1980 .{ }^{\mathrm{b}} 1985 .{ }^{\mathrm{c}}$ Includes general secondary school.

Source: Donors to African Education (1994).

Zimbabwe. ${ }^{14}$ Unfortunately, measures of expenditure per primary-school student can be deceptive, because if teachers' salaries are relatively high and enrollments are relatively low, a less inefficient system can appear to be doing better than a system that is more efficient and is serving more students. Countries with high per-pupil expenditures include those that are known to be doing well on other measures (that is, on the percentage 
of GNP devoted to educational expenditures and on the percentage of educational expenditures devoted to primary schooling) such as Botswana, Cameroon, South Africa, and Zimbabwe, and others that are not, such as the former French colonies of Mali and Senegal, where relative salaries for teachers are known to be high.

\section{The QUALITY OF EdUCATIONAL DATA}

Most of what we know about trends in primary schooling in developing countries comes from annual statistics produced by UNESCO on gross primary-school enrollment ratios. Censuses, which always include questions on the educational participation and attainment of the population, are only conducted every ten years, and the published results are often delayed, given limited circulation, and produced in a form that is rarely comparable with other censuses. Although they constitute another source of data on educational participation for particular countries, national household surveys have never been compiled in such a way that they can be used comparatively as an alternative source of data on education. Only in the last few years has the Demographic and Health Survey (DHS) program, which has been collecting information systematically on educational participation and attainment of household members in all surveys since 1990, begun to allow researchers an alternative perspective on educational levels and trends in a substantial number of developing countries (Gardner 1998; Filmer and Pritchett 1999).

To construct enrollment ratios, UNESCO uses United Nations population estimates of the size of the primary-school population combined with official reports from education ministries of numbers enrolled in primary school. Thus, the gross primaryschool enrollment ratio is calculated as the number of children of any age enrolled the primary-school level divided by the number of children of the appropriate age to attend that level. ${ }^{15}$ This calculation provides a crude indicator of participation rates in primary school. Because of late ages of entry as well as grade repetition, however, these levels and trends are sometimes hard to interpret. Ages in the numerator of the ratio are not consistent with ages in the denominator, and therefore ratios greater than 100 are possible. Furthermore, a decline in the ratio could reflect a decline in enrollment or, alternatively, could imply improvements in the efficiency of the system through reductions in repetition rates or a shift toward more appropriate ages at entry. Similarly, a rise in the ratio could imply a rise in enrollment rates or, alternatively, a deterioration in the effi- 
ciency of the system due to rising repetition rates or delayed ages of entry. More typically, trends probably reflect simultaneous changes in a variety of underlying factors, some of which may be more favorable and some less. Given scarce resources, schools and district education offices have every incentive to provide inflated numbers to the central authorities in order to secure necessary funding. In addition, some evidence suggests that enrollment as reported by school systems reflects opening-day numbers rather than enrollments in mid-year or year-end, which would reflect experience more accurately (Behrman and Rosenzweig 1994).

Probably for all of the reasons enumerated, recent compilations of social indicators have sought alternatives to gross primary- or secondary-school enrollment ratios when constructing measures of educational and social progress. For example, the $\mathrm{Hu}$ man Development Index (HDI) constructed by the United Nations Development Program (UNDP 1997) relies mainly on literacy rates for the adult population for identifying one of three components of the index designed to capture the educational attainment of the population. ${ }^{16}$ In order to avoid combining population-based data with incompatible school-based data, the United Nations Children's Fund (UNICEF), in its annual assessment of The Progress of Nations, now uses a measure of the proportion of children completing four years of school, which is derived from year-by-year school-enrollment data provided by education ministries (UNICEF 1993). These percentages, although free of the biases inherent in relating school-based data to population-based data, are still subject to the whims of education ministries where the politics of education finance may lead to unpredictable distortions.

Using a gross enrollment ratio of 90 as a measure of mass schooling, UNESCO data imply that 13 African countries had achieved mass schooling by 1980 . Two more countries would appear to have joined the group in 1985, but by the mid-1990s the number of countries with mass schooling as defined by the gross enrollment ratio had fallen to eight. These are Botswana, Kenya, Lesotho, Namibia, South Africa, Togo, Zambia, and Zimbabwe, all of which have calculated enrollment ratios consistently above 90 since 1980 at least. Countries that had dropped off the list include Angola, Cameroon, Congo, Madagascar, Mozambique, Nigeria, and Tanzania. Although we know that many countries suffered setbacks in the educational sector in the 1980s and early 1990s as a result of economic reversals (the cases of Nigeria and Tanzania are particularly no- 
table), it is implausible that many of the countries on the list in 1980 had ever attained near-universal primary enrollment. Comparisons of current school-attendance rates from recent DHS surveys for children aged 10-11 with UNESCO's gross enrollment ratios ${ }^{17}$ show that population-based participation rates are almost always lower than the levels of primary-school participation implied by gross enrollment ratios and often lower by a substantial margin (as Table 4 demonstrates). Such comparisons provide further confirmation of the problematic nature of enrollment ratios as a measure of educational participation.

Table 4 Percentage of children aged 10-11 enrolled in school and gross primary enrollment ratios for 16 sub-Saharan countries, by country and year, Demographic and Health Surveys and UNESCO

\begin{tabular}{lrcc}
\hline Country & Year & $\begin{array}{c}\text { Currently enrolled } \\
\text { (DHS) }\end{array}$ & $\begin{array}{c}\text { Gross primary } \\
\text { enrollment ratio } \\
\text { (UNESCO) }\end{array}$ \\
\hline Burkina Faso & 1993 & 32 & 39 \\
Cameroon & 1991 & 76 & 96 \\
Côte d'Ivoire & 1994 & 55 & 68 \\
Ghana & 1993 & 82 & $76^{\mathrm{a}}$ \\
Kenya & 1993 & 90 & 91 \\
Madagascar & 1992 & 69 & 76 \\
Malawi & 1992 & 67 & 80 \\
Mali & $1995-96$ & 30 & $32^{\mathrm{b}}$ \\
Namibia & 1992 & 89 & 136 \\
Nigeria & 1990 & 65 & 85 \\
Senegal & $1992-93$ & 40 & 59 \\
South Africa & 1993 & 97 & 115 \\
Tanzania & $1991-92$ & 66 & 70 \\
Uganda & 1995 & 80 & $67^{\mathrm{c}}$ \\
Zambia & 1992 & 83 & 87 \\
Zimbabwe & 1994 & 93 & $115^{\mathrm{c}}$ \\
\hline
\end{tabular}

Note: Botswana is omitted from the table because DHS data on education are available only for females aged 15-49.

${ }^{\mathrm{a}} 1991 . \quad{ }^{\mathrm{b}} 1994 .{ }^{\mathrm{c}} 1993$.

Sources: UNESCO (1997) and Gardner (1998). For South Africa, South African Labour and Development Unit (1993). 
The ideal source of educational participation data for pan-African comparisons would be recent population censuses, because they are designed to cover the whole population and because both current enrollment rates and past attainment rates as far back as independence can be derived from these data. Unfortunately, results of recent censuses are not easily available in published form, much less in computer-readable form and, therefore, cannot be used to provide a full picture of levels and trends in educational participation since independence in Africa. Those that are available, however, can be used for comparison to assess the quality of the data from the DHS, which are based on relatively small samples of the census population. Censuses are imperfect and frequently miss certain portions of the population that are difficult to reach and that are, therefore, likely to have less access to educational resources than others, whether for political, economic, or geographic reasons. Because surveys are usually drawn from sampling frames developed for the census, they may also have similar biases. In the sample of ten countries considered here for which comparisons are possible, we would expect that samples drawn from the census would be as likely to underestimate as to overestimate proportions enrolled in school. A systematic bias in one direction or another would raise additional questions about survey estimates.

Figures 1a-1c present recent census data on trends in the proportion of the population of ten countries by age that never enrolled in school. The data shown are for Cameroon (1987), Ghana (1984), Kenya (1989), Malawi (1987), Mali (1987), Namibia (1991), Uganda (1991), Tanzania (1988), Zambia (1990), and Zimbabwe (1992). ${ }^{18}$ For each of these countries, percentages that never enrolled are also calculated by age from DHS data on a comparable basis by adjusting the ages to reflect the number of years that elapsed between the most recent census and the DHS survey. ${ }^{19}$ Figure 1a shows results for the three countries for which data are largely consistent; Figure $1 \mathrm{~b}$ shows results for the four countries for which differences emerge for some age groups; and Figure 1c shows results for the three countries for which data appear inconsistent over a broader range of ages. Although the consistency of the DHS and census estimates of levels and trends in school participation for Namibia, Tanzania, and Zimbabwe is reassuring (see Figure 1a), the estimates for the other seven countries are disconcerting. The census estimates always imply a slightly less educated population than that implied by the DHS 


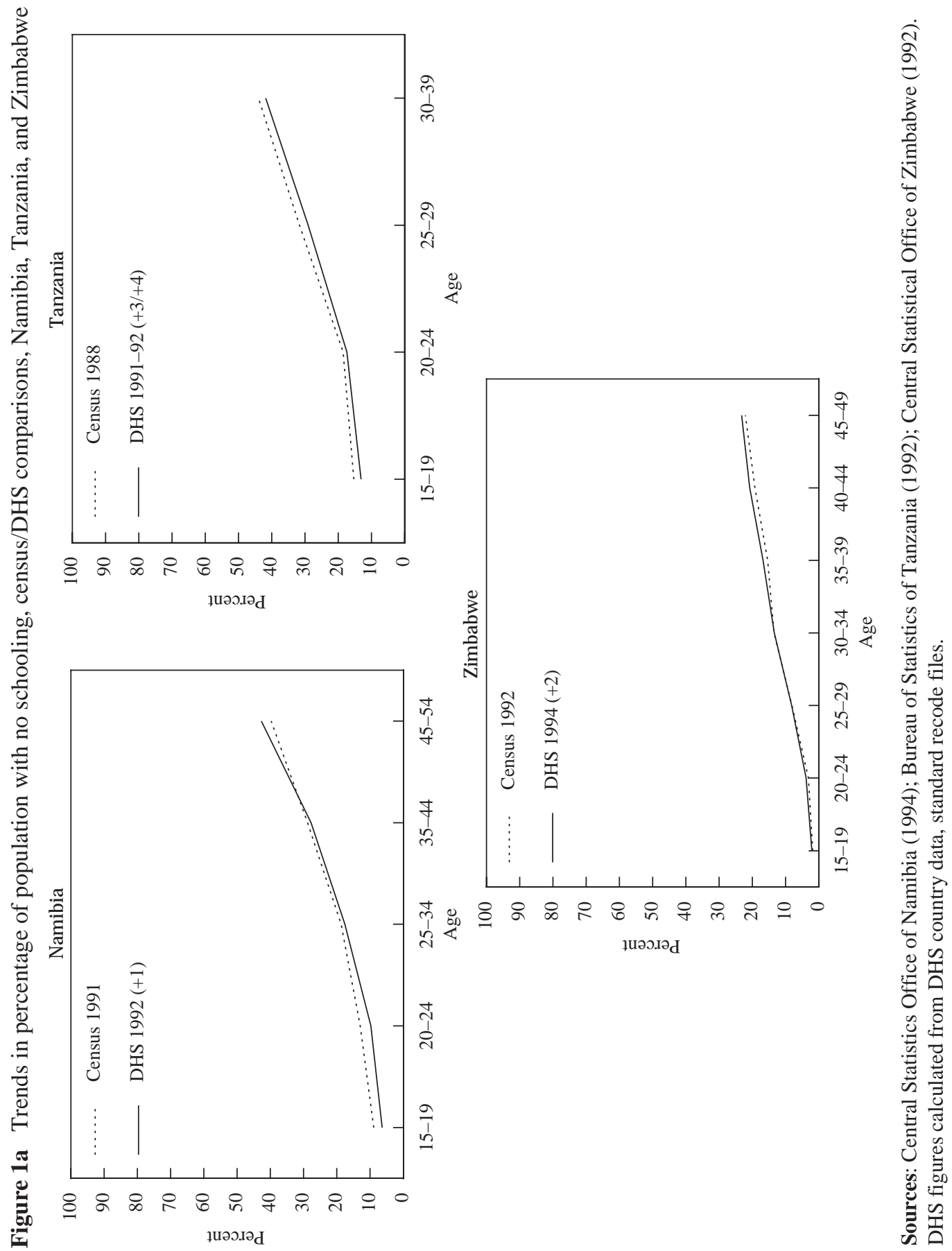




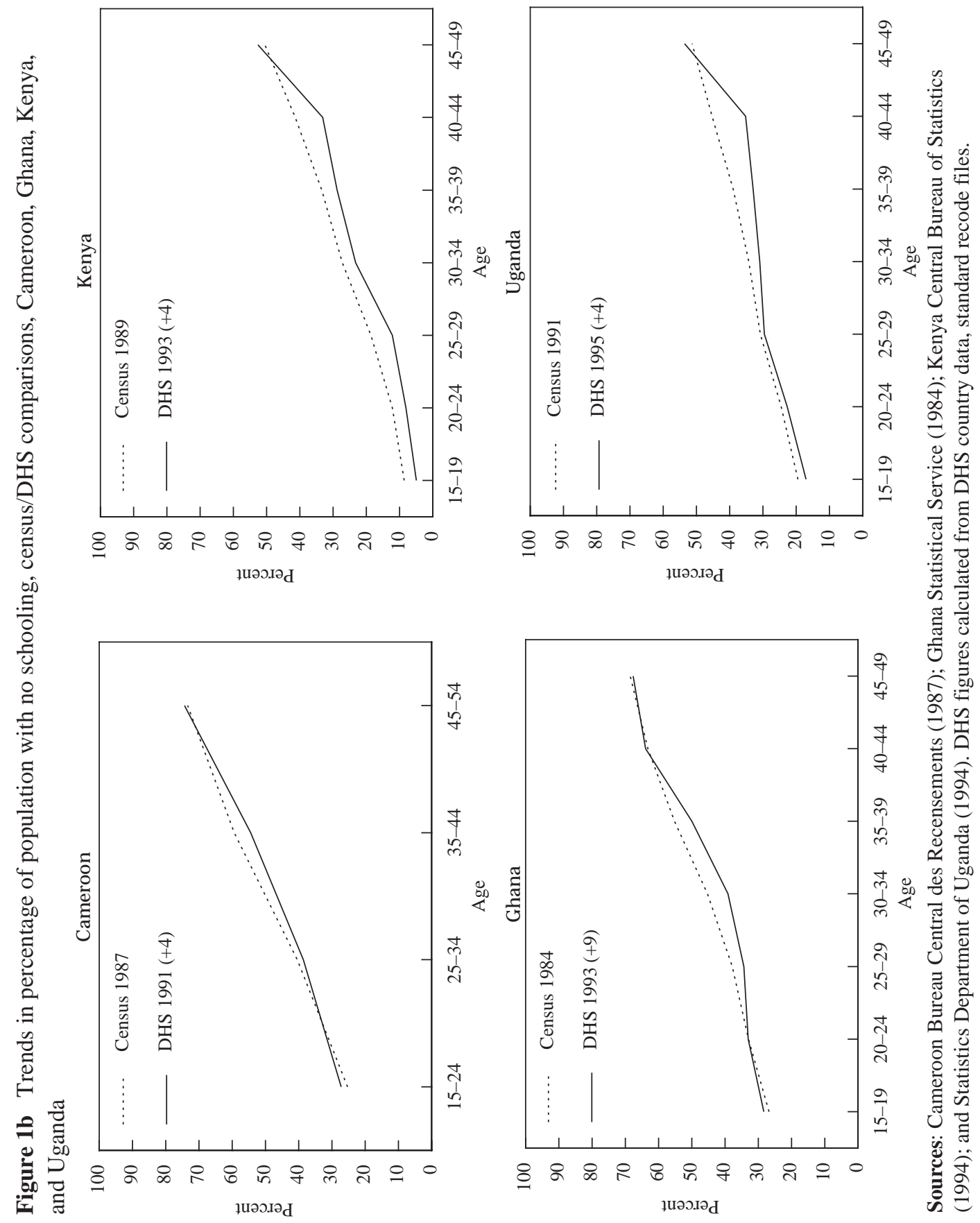



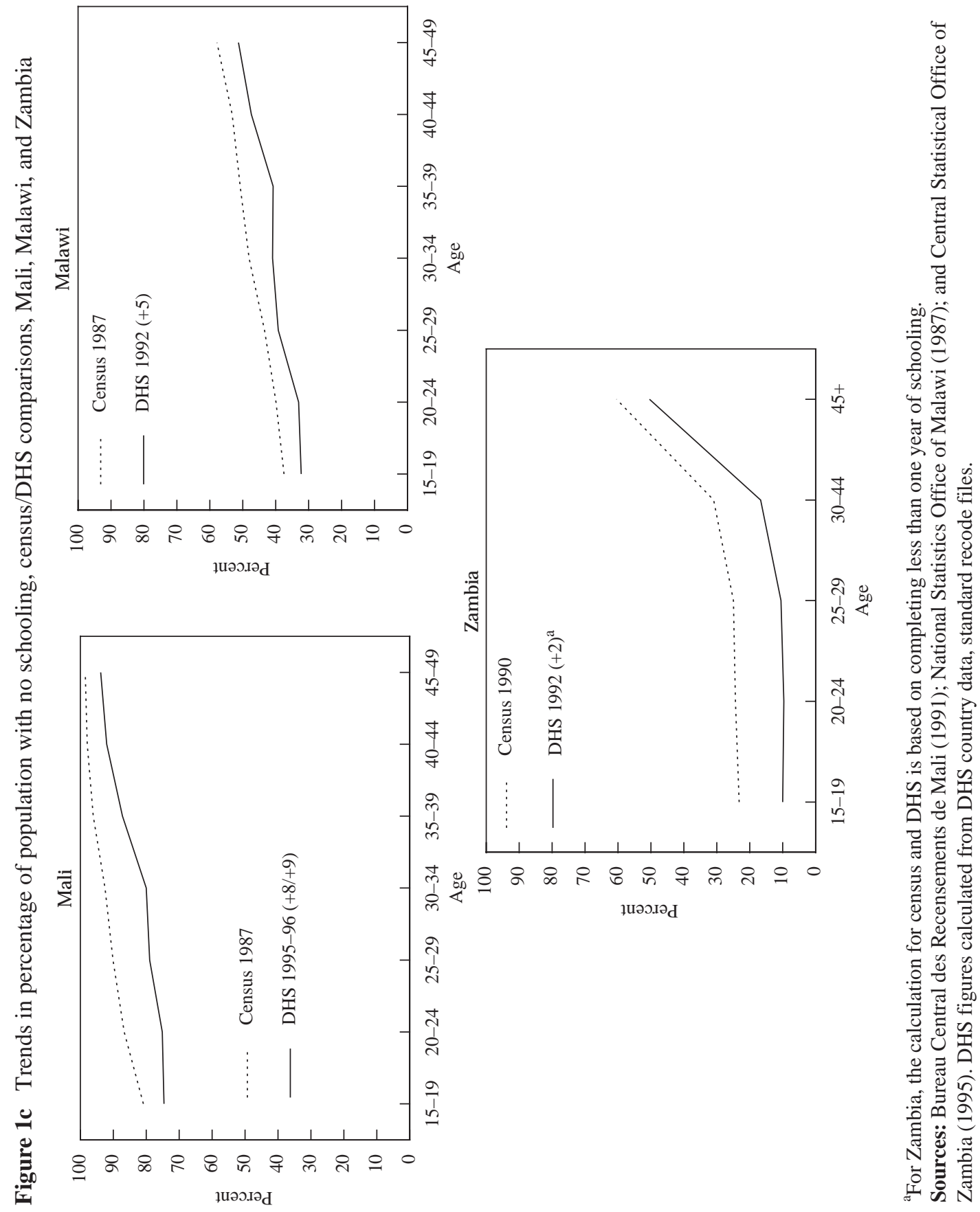
data. These differences are relatively small in the cases of Cameroon, Ghana, and Uganda (see Figure 1b) where only some age groups are affected, but the effects are larger for women than for men (not shown) and differences as great as 6-10 percentage points emerge in the peak reproductive years in Ghana (25-39) and of 6-8 percentage points among 35-44-year-old women in Uganda. In Kenya, the differences are more consistent across the age spectrum, with differences ranging from 3-9 percentage points. The biggest differences emerge for Mali, Malawi, and Zambia (see Figure 1c). Of these three countries, the differences are greatest for Zambia, where the gaps range from 12-15 percentage points. Although both sources of data imply similar trends in the proportion ever attending school, the census suggests a less educated population than that implied by the DHS.

The percentage with no schooling reflects only one extreme of the educational distribution. In most of these countries, significant progress has been made over the years since independence in enrolling children in school. A more telling comparison between the data from these two sources would be the proportion completing primary school. Unfortunately, censuses did not adopt consistent approaches to the measurement of educational levels despite the effort of the UN to recommend certain uniform guidelines. ${ }^{20}$ Some census questionnaires ask about grades completed and some ask about years of education attained. Furthermore, census reports do not always make clear which approach was used. Here, a comparison of primary-school completion rates from the census and the DHS data is possible for only three of the ten countries presented in Figures $1 \mathrm{a}-\mathrm{c}$. These were the only countries for which definitions of education attained were unambiguous and for which published tables could be replicated using the DHS data. Figure 2 presents trends in primary completion rates for Kenya, Zambia, and Zimbabwe (in the cases of Kenya and Zambia, which have eight years of primary schooling, the completion of five or more years was used). In all three cases, the census data imply a less educated population than do the DHS data, with the gap widest at the youngest ages. ${ }^{21}$

The stated goal of this paper is to test Caldwell's mass-schooling hypothesis for Africa, linking the arrival of mass schooling with declines in fertility. These census/ DHS comparisons raise questions about whether we can know with confidence, using DHS data alone, which countries have achieved mass schooling and, if so, when that 


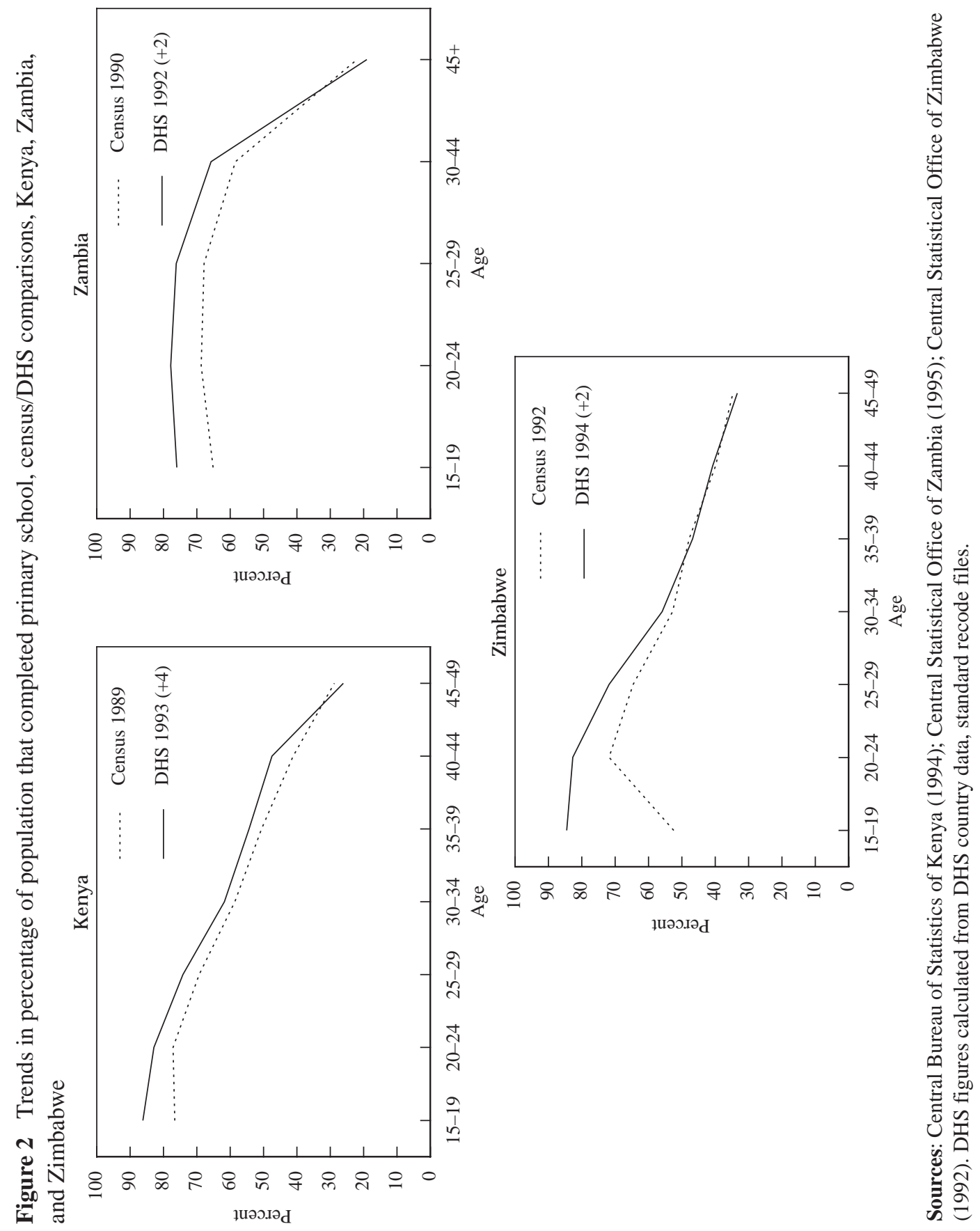


might have occurred. Moreover, timing the fertility transition requires accurate measures of fertility. In light of the close link between educational distributions and estimated fertility rates, current levels of fertility for some countries, as derived from DHS surveys, could be at least slightly underestimated and, for other countries, estimated recent fertility trends could be slightly exaggerated. Census data, of course, are not a gold standard for data comparisons; indeed, censuses are often notorious for underrepresenting certain groups whether because of socioeconomic disadvantage, geographic isolation, or political disenfranchisement. DHS samples, however, use census data for sampling frames, which would suggest that biases in censuses would be closely mirrored in DHS samples. Although in many cases, DHS and census estimates match one another closely, in those cases with differences, DHS samples are consistently more educated. Further speculation on biases for these data sources on sub-Saharan African education is difficult. Whether education data are derived from the DHS or from censuses, however, any bias in the data probably tends toward an overestimate of educational attainment.

\section{PATterns AND TRENDS OF FORMAL SCHOOLING}

Colonial legacies in education, uneven political commitment, and economic fluctuations have shaped trends in schooling across countries in sub-Saharan Africa profoundly. As noted above, most studies tracing trends in education have used UNESCO's gross enrollment ratios and thus present an inflated and inaccurate picture. Therefore, before exploring the association between fertility patterns and the provision of mass schooling, we first reconsider trends and patterns of education in the region using data from 17 of the sub-Saharan DHS household surveys, including all the countries that are known to be leaders in educational investments. ${ }^{22}$ Using the educational distribution of the population by age in the most recently available DHS surveys, the educational attainment of 15-19-year-olds is estimated at various points in the past by calculating in which year each age cohort would have been 15-19 years old. To the extent that systematic biases exist in age reporting and to the extent that survival rates differ significantly by educational attainment, estimates of trends will be biased. Because of differential survival rates by education, we would expect that older cohorts would appear more 
educated than they actually are, with the bias being greatest for the earliest estimates in 1960 and lessening since then. Typical errors of age rounding are also likely to flatten trends. These biases are not expected to affect cross-country rankings in schooling levels seriously, however.

Caldwell defined the achievement of mass schooling as the point at which 90 percent of primary-school-aged children attend school. To operationalize attendance at primary school, a broad definition is used here: The percentage of 15-19-year-olds who have ever attended school is calculated. ${ }^{23}$ Figures $3 \mathrm{a}$ and $3 \mathrm{~b}$ show the results for successive cohorts of 15-19-year-olds, starting in 1960 and continuing through the most recent year for which data are available. Several points are illustrated strikingly in these graphs. First, and not surprisingly, the 1960 level of attendance across all countries falls well below levels required for mass schooling and, considering the biases noted above, these data can be taken as confirmation of the inadequate reach of colonial schooling systems. Second, countries of West Africa (Figure 3b), comprising former colonies of both Britain and France, have a notably lower level of attendance for 1960 than those in southern and eastern Africa (Figure 3a), most of which are former British colonies. Of the West African countries, the former French colonies of Burkina Faso, Côte d'Ivoire, and Senegal lag considerably behind the former British colonies (including Cameroon, which was colonized by both Britain and France). Viewing changes over time, most countries have made substantial progress in facilitating school attendance for children.

All countries show clear increases in the percentage of children who attend school, although, consistent with spending trends and state educational strategies, the levels of attendance achieved by the former French colonies of West Africa are, in general, not as great as those achieved in the former British colonies. Extremes within each region exist, reflecting specific agendas and economic conditions. In East Africa, for example, the poor, land-locked country of Malawi had set the transport of goods and labor, rather than education, as a priority (Nieuwenhuis 1996), while Kenya saw to it that educational expenditures, especially for primary schooling, continued to grow. Figure $3 \mathrm{a}$, accordingly, shows that Malawi has experienced about a 25 percentage point increase in attendance between 1960 and 1992, although, with only 75 percent of 15-19-year-olds currently attending school, the country is far from attaining an ideal of universal schooling. 
Figure 3a Trends in the percentage of children aged 15-19 who ever attended school, southern and eastern Africa

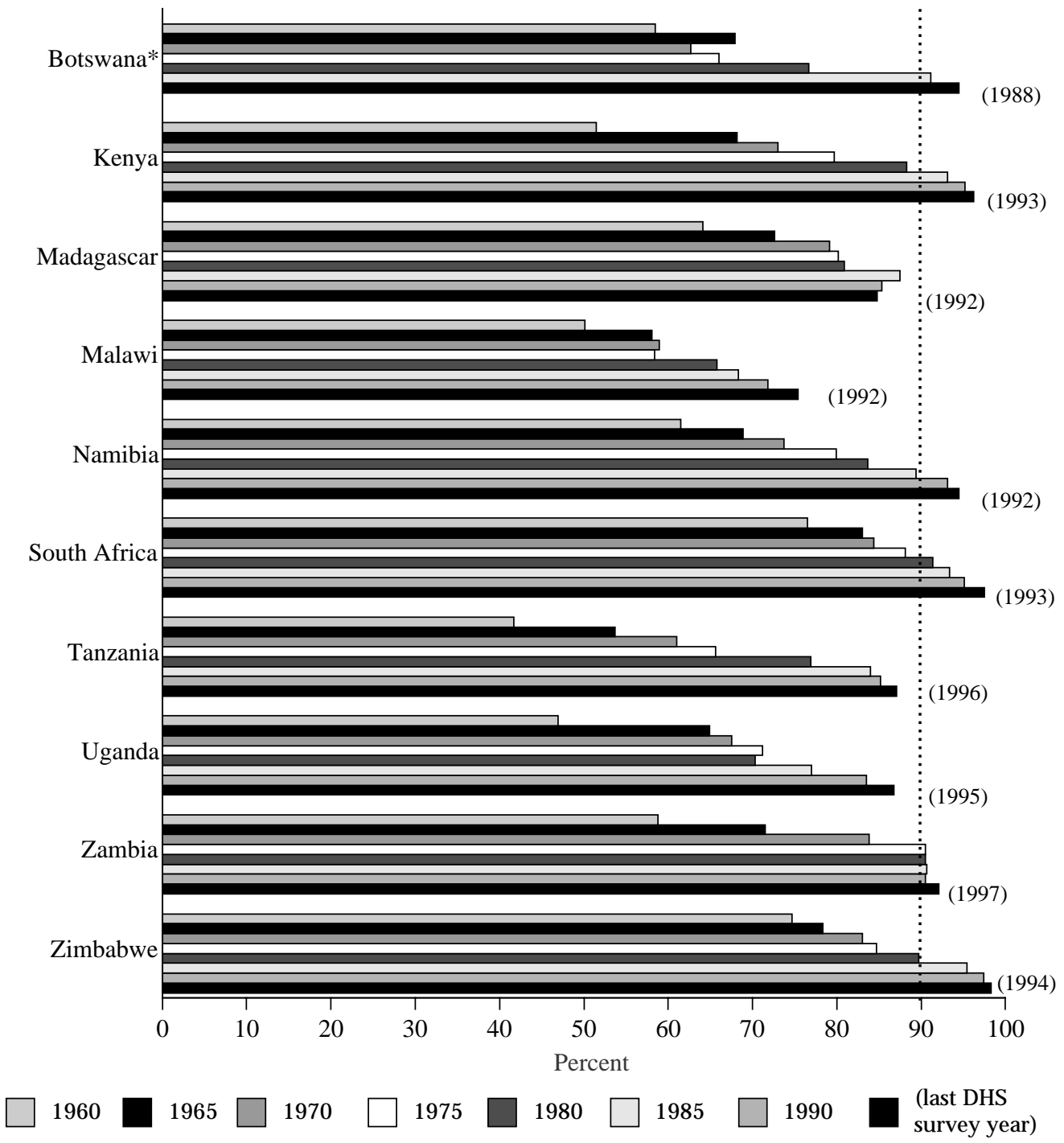

*Women aged 15-49.

Sources: DHS figures calculated from DHS country data, standard recode files. 
Figure 3b Trends in the percentage of children aged 15-19 who ever attended school, West Africa

Mass-schooling level

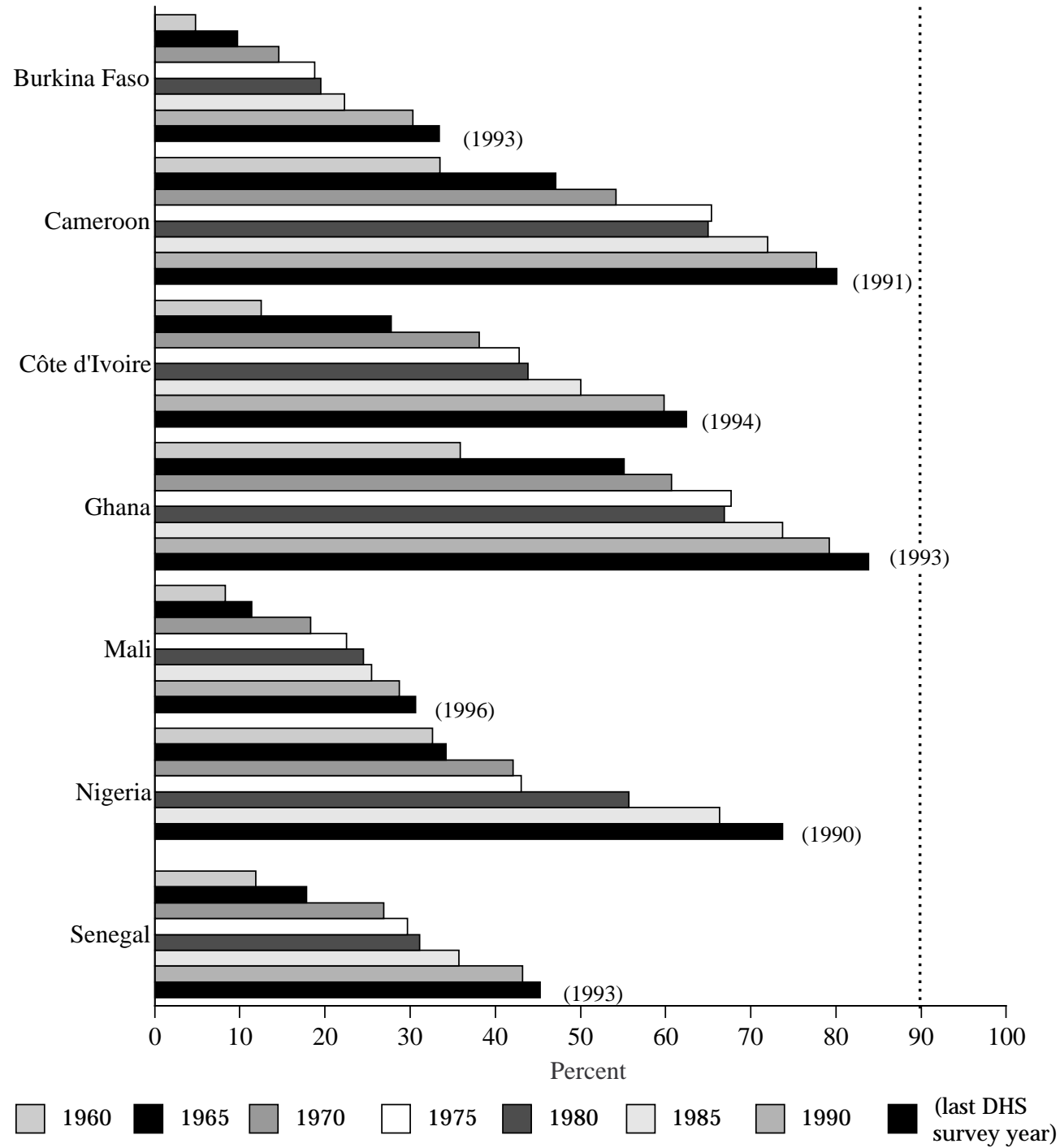

Sources: DHS figures calculated from DHS country data, standard recode files. 
Kenya, on the other hand, shows close to a 45 percentage point increase for children attending school, so that by 1993, almost 95 percent of 15-19-year-olds had attended school at some point in their lives, a level just below that for South Africa. In the West African countries of Cameroon, Ghana, and Nigeria in 1960, only about 35 percent of 15-19-year-olds had ever attended school, and in Cameron and Ghana, this level climbs to more than 80 percent for the most recent time period. Although these countries are still some distance away from achieving Caldwell's definition of mass schooling, the data nonetheless represent an impressive 45 percentage point gain in school attendance. The cases of Ghana and Nigeria are particularly impressive because secondary and tertiary schooling received a disproportionate share of these countries' education budgets. In Burkina Faso and Mali in the mid-1990s, by contrast, fewer than 35 percent of 1519-year-olds had ever attended school for the last date available. Although this number still represents a 20 percentage point gain for children who go to school, the proportion remains abysmally low.

In spite of evident progress, the figures are also striking in showing that so few countries meet Caldwell's definition of mass schooling. In only six countries, Botswana, Kenya, Namibia, South Africa, Zambia, and Zimbabwe, have at least 90 percent of 15-19-year-olds ever attended school. Furthermore, for most of these countries, that level of schooling had already been achieved some 15 to 20 years ago. Zambia-the country showing the greatest inconsistencies in estimates of educational participation between the census and the DHS - appears to have crossed this threshold first, in the mid-1970s, and seems to have remained more or less at that level since then. This finding is congruent with a colonial policy emphasizing broad access to primary education (Kelly 1991) and strong economic growth and massive expenditures on education in the first postindependence decade (Nieuwenhuis 1996). South Africa reached the threshold in the late 1970s, followed quickly by the other four countries in the early to mid-1980s. Furthermore, evidence from Madagascar, which shows a decline for the most recent period, suggests that a trend toward mass schooling is not irreversible.

The point that mass schooling is a rare phenomenon in sub-Saharan Africa is even more striking if one considers that the trends displayed in Figures $3 \mathrm{a}$ and $3 \mathrm{~b}$ represent only the point of entry into the educational system. The designation "ever attended 
school" indicates whether children had walked into a classroom; the measure does not indicate how long they stayed. As noted earlier, Caldwell's discussion of mass schooling was informed by a Western experience where mandatory schooling was enforced. Few countries in sub-Saharan Africa have the capacity to enforce regular school attendance; many children might begin school but few may complete even a primary-level education. Two measures are used here to describe the depth of schooling, that is, to show how long children remained in school. One is the percent of 15-19-year-olds who have completed a primary education, however that level may be defined in their own countries. Because of the variation across countries in the duration of primary schooling (for example, Kenya's primary schooling consists of eight grades, whereas Madagascar's has only five), we also compare the percentage of 15-19-year-olds who have completed at least four years of schooling - a measure that can be interpreted consistently across countries.

The trends in completion of at least four years of schooling illustrate the challenges in ensuring that children who begin school complete even a few grades (see Figures $4 \mathrm{a}$ and $4 \mathrm{~b}$ ). To facilitate a comparison of countries' achievements in attaining depth in mass schooling, we chose, somewhat arbitrarily, 75 percent of 15-19-year-olds who have completed four years of school as a threshold marking mass-schooling progress. The threshold is well below the 90 percent level of "ever-attended" used by Caldwell, but nevertheless indicates that some depth of education is pervasive in the population. Eight of the 17 countries in this comparison have surpassed the 75 percent threshold, and with the exception of Ghana, they are all southern or eastern countries. Most countries crossed this threshold in the late 1970s, indicating that some depth of education has accompanied the wider attendance described above. The progress has been slow, however. A few countries, including Burkina Faso, Madagascar, Mali, Malawi, and Senegal, have registered little net change in the past three decades. The trends in general are consistent with those described for the measure "ever attended," and they reflect the ebbs and flows of state finance and the intrasectoral priorities of educational expenditure. The former French colonies of West Africa show only small gains in the percentage completing at least four years of school, and are at some distance from the 75 percent mark. The West African countries that are former British colonies, by contrast, show 
Figure 4a Trends in the percentage of children aged 15-19 who completed four or more years of schooling, southern and eastern Africa

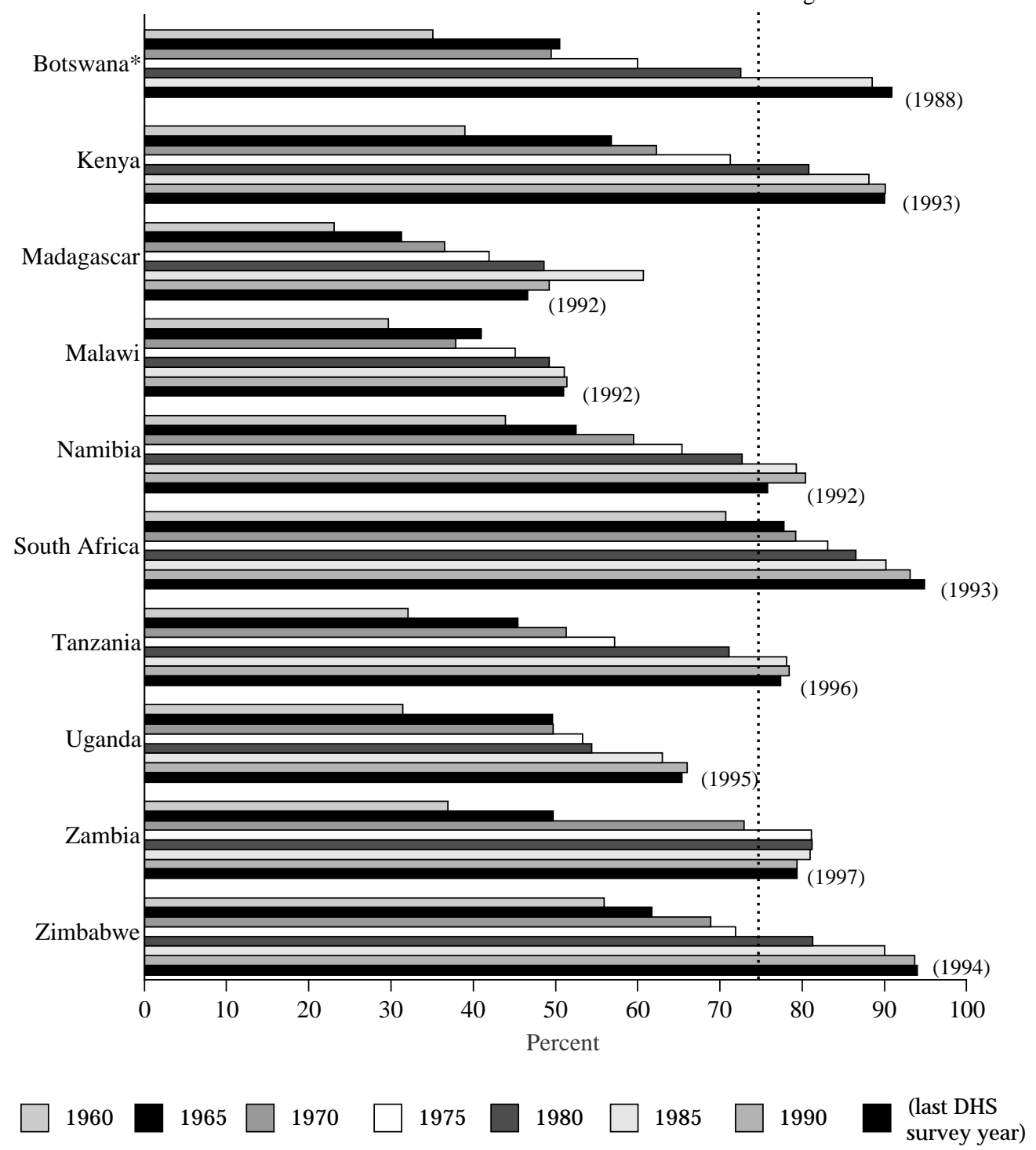

*Women aged 15-49.

Sources: DHS figures calculated from DHS country data, standard recode files. 
Figure 4b Trends in the percentage of children aged 15-19 who completed four or more years of schooling, West Africa

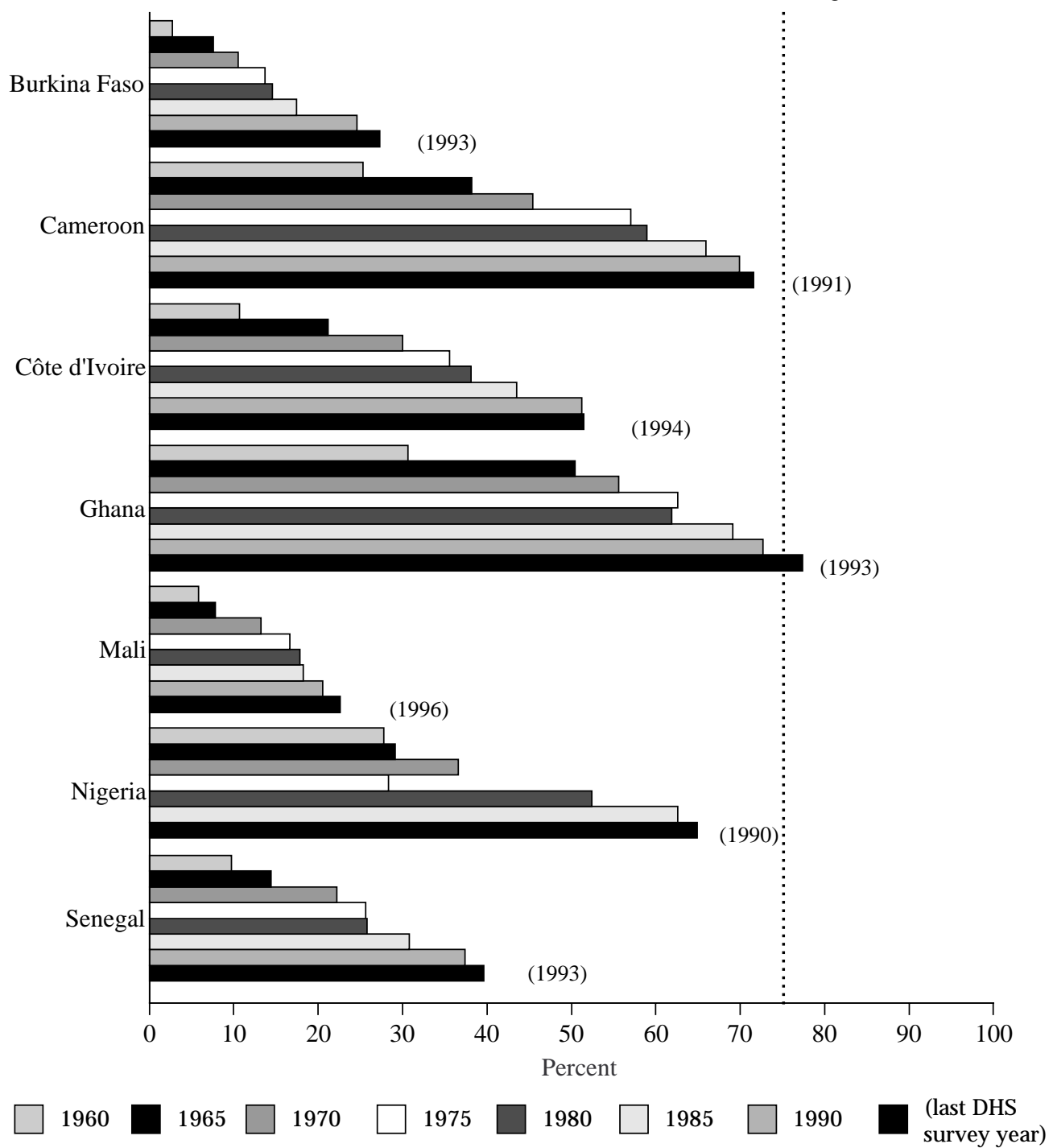

Sources: DHS figures calculated from DHS country data, standard recode files. 
steeper inclines and are much closer to (or in the case of Ghana, just at) the 75 percent mark. As mentioned above, most countries of West Africa gave greater priority to secondary and tertiary education, which probably explains the lag in levels there compared with southern and eastern countries, which tended to allot proportionately more resources to primary education. However, while countries of West Africa have continued to show increasing trends, albeit at relatively low levels, countries of southern and eastern Africa reached plateaus in the mid 1980s, and further indication of increases there are absent. Three countries, Madagascar, Namibia, and Zambia, exhibit declines.

The slow and fragile progress in the depth of schooling hinted at in Figures $4 \mathrm{a}$ and $4 \mathrm{~b}$ is repeated more boldly in the trends describing primary-school completion for 15-19-year-olds (as shown in Figures 5a and 5b). Because young people aged 15-19 at the time of the survey have not all had a chance to complete primary school as the result of these late ages of entry, the assessment of trends in primary-school completion does not extend beyond 1990. Again, to facilitate comparison, we chose a 60 percent level as a threshold to indicate that more than half of the population has completed primary school - a modest but notable achievement for most countries in the region. Only Botswana, Ghana, Kenya, South Africa, Tanzania, and Zimbabwe had achieved this level by $1990 .{ }^{24}$ Similar to patterns for other measures, Zambia was a front runner in surpassing the 60 percent mark, but since the early 1970s, the level for Zambia has declined below that threshold. Most other countries in southern and eastern Africa also have shown recent declines or plateaus that compromise the impressive gains of the late 1970s and early 1980s (Botswana, South Africa, and Zimbabwe are the exceptions). Other than Ghana, most West African countries in the sample show evidence of stagnation since the late 1980s (anecdotal evidence suggests that this is the case for Nigeria as well), a probable manifestation of the sharp decline in the growth rate of educational expenditure in the region. The slowdown is particularly alarming because many of these countries currently remain at very low levels of primary-school completion. Burkina Faso, Côte d'Ivoire, Mali, and Senegal show levels of completed primary school below 35 percent, levels not much higher than those of three decades past. The low levels in West Africa are even more remarkable because these countries devote fewer years to the primaryschool curriculum than do countries in other parts of sub-Saharan Africa. All West Afri- 
Figure 5a Trends in the percentage of children aged 15-19 who completed primary school, southern and eastern Africa

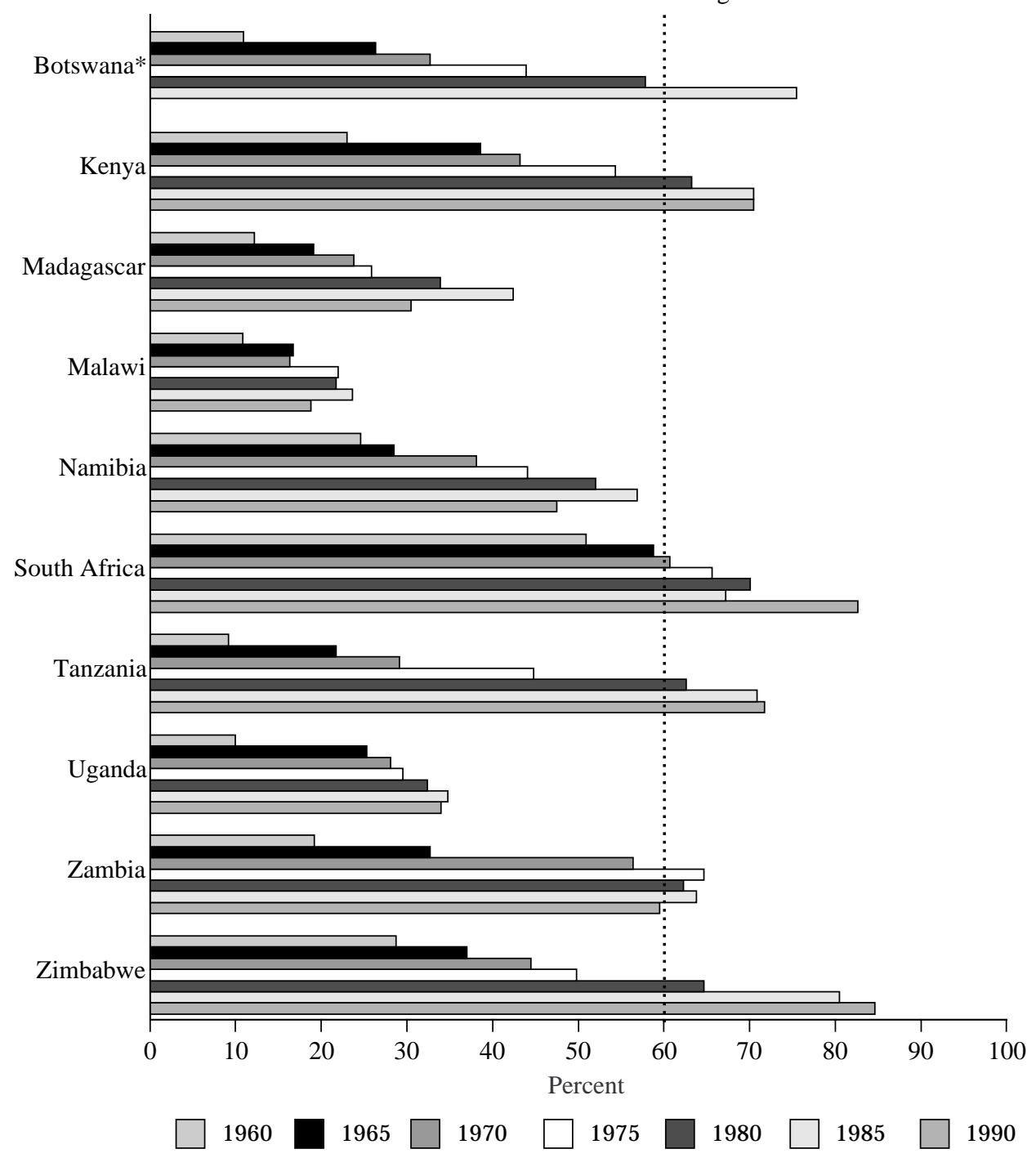

*Women aged 15-49.

Sources: DHS figures calculated from DHS country data, standard recode files. 
Figure 5b Trends in the percentage of children aged 15-19 who completed primary school, West Africa

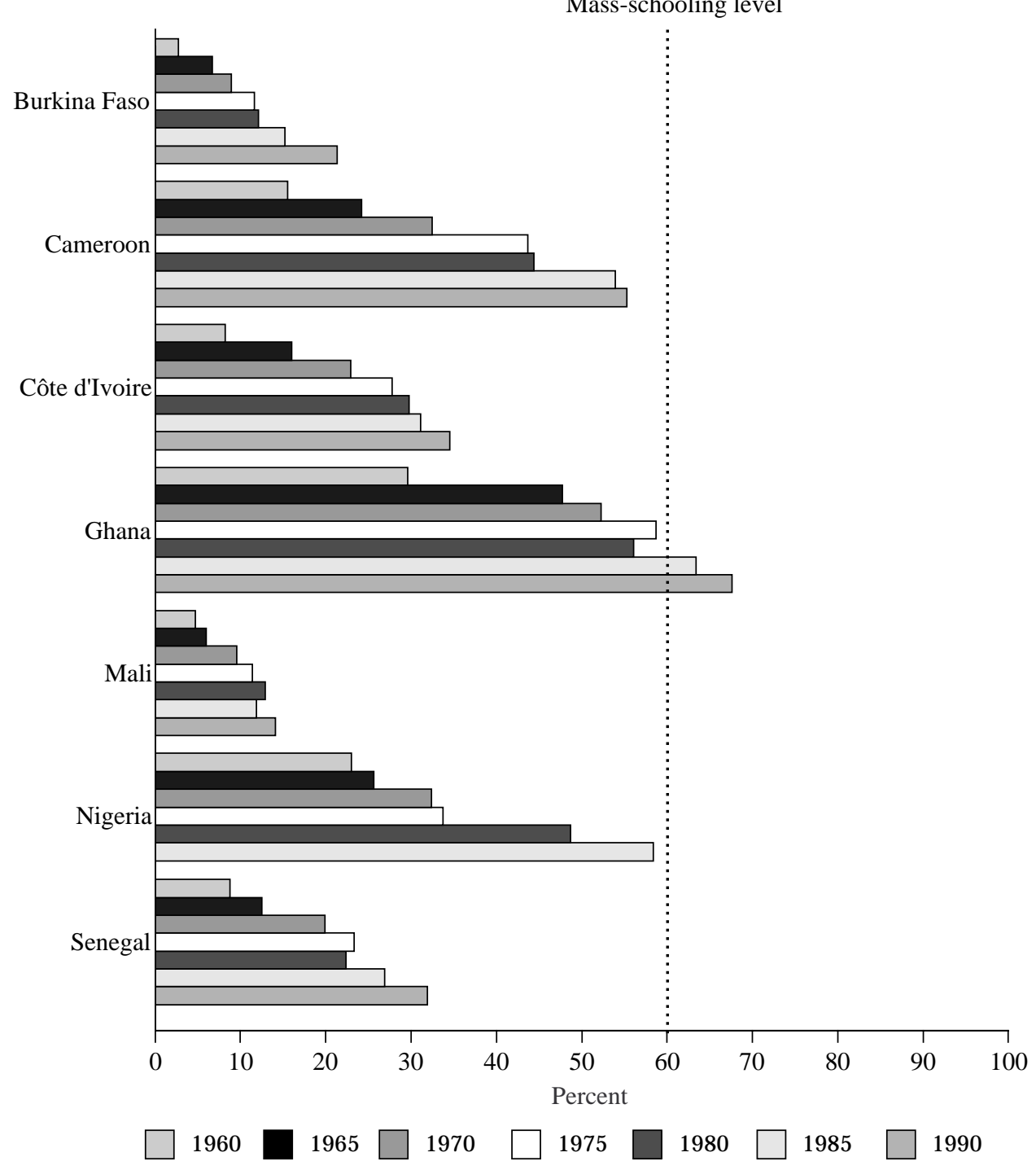

Sources: DHS figures calculated from DHS country data, standard recode files. 
can countries in the sample require six years for primary school, except for Madagascar, which requires only five. All countries in southern and eastern Africa require seven years, except for Kenya and Malawi, which require eight (UNESCO 1997). Only in the case of Kenya might the plateau in primary-school completion be attributed at least in part to reforms in the educational system. The 1985 reform in Kenya changed the requirement for primary school from six to eight years (Husén and Postlethwaite 1994), and Kenya's decline from that point on may reflect the difficulty that many children have in attending school for an additional two years. No other country in the sample recast its requirements for schooling at the primary level (UNESCO 1997). The stagnation in primary-school completion is probably one manifestation of the economic hardships of the 1980s and early 1990s (see, for example, Ogbu and Gallagher 1991; Reimers 1994; and Grootaert 1994).

The widespread stagnation in the percentage completing four years of education and in that completing primary school is considered here as background for an evaluation of how these overall trends and patterns are played out by sex. Have these countries made gains in achieving gender equity in school attendance or in years completed? Has the recent stagnation, and in some cases declines, in schooling completion adversely affected girls? Figure 6 presents the ratio of the percentage of female to male students who completed four or more years of schooling. A ratio of one indicates perfect equity between boys and girls, a ratio of less than one indicates that a greater percentage of boys than girls completed four years of school. Only the measure of four years completed is presented because this measure is directly comparable across countries, but the trends in gender equity are similar for all three measures of education. Finally, for ease of presentation, trends in ratios only for a select number of countries are provided. The countries chosen represent extremes (Mali and Namibia), or they represent several typical patterns found throughout sub-Saharan Africa. ${ }^{25}$ Figure 6 shows that for most countries, increasing number of girls relative to boys have been completing at least four years of education. This change is as true of countries at low levels of overall completion (for example, Mali) as it is of countries with relatively high levels of completion (for example, Kenya). The trends warrant a note of caution, however. Prior to 1990, what had been driving the ratios toward a value of one (and occasionally beyond) was a 
Figure 6 Trends in the ratio of the percentage of females to the percentage of males aged 15-19 who completed four or more years of schooling, selected countries, sub-Saharan Africa

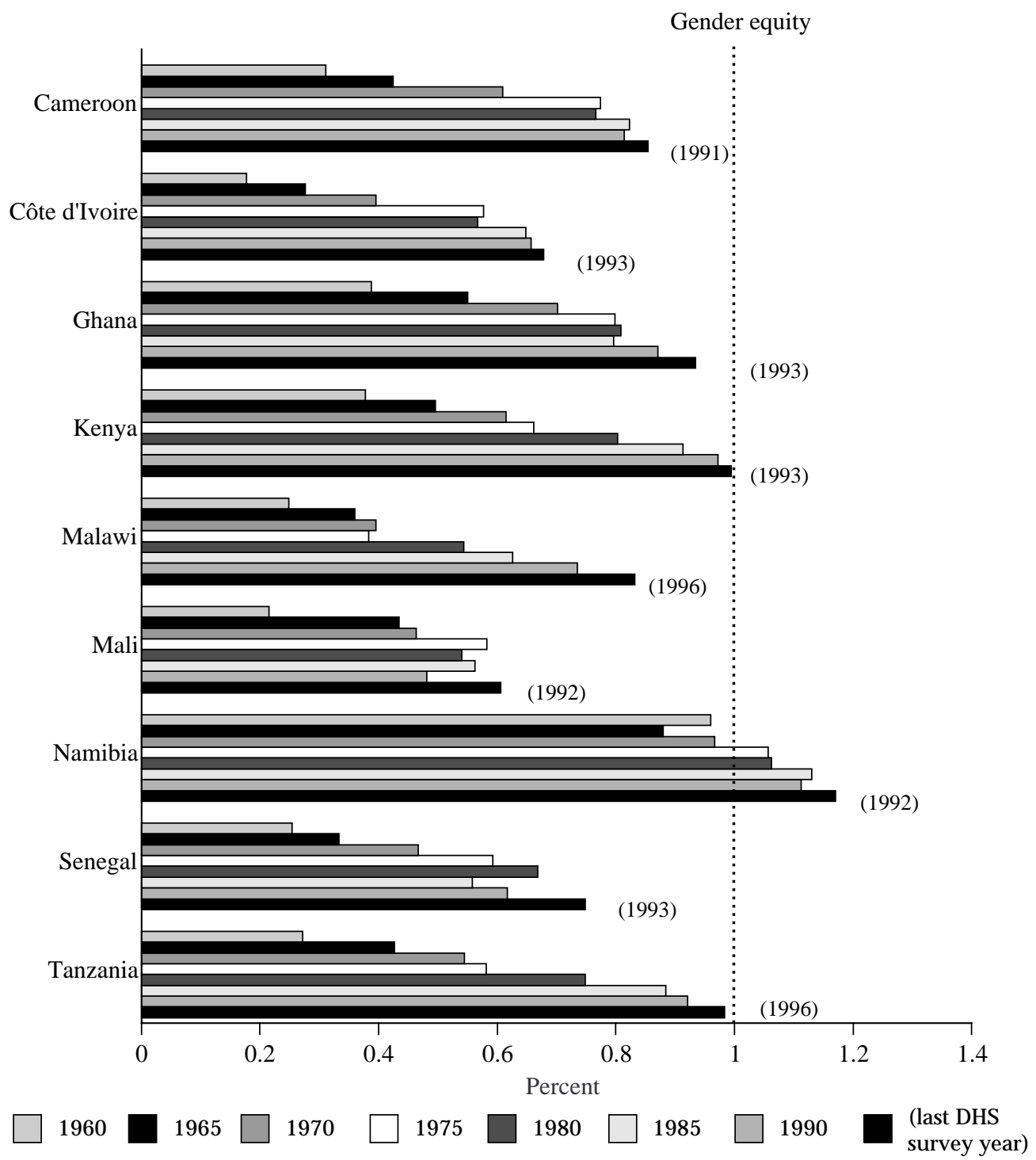

Sources: DHS figures calculated from DHS country data, standard recode files. 
steady increase in levels for both sexes. More recently, however, the proportion of boys completing four years of school has exhibited no improvement or has shown a downward shift in many countries. The sharp increases in ratios displayed in the graph for Cameroon, Côte d'Ivoire, Mali, Malawi, Namibia, and Tanzania are examples of declining rates for boys, whereas the rates for girls continue to increase. Rose (1995) notes that the decline in boys' enrollment has occurred primarily in those countries participating in World Bank-supported adjustment programs. Although Rose does not discuss the factors underlying these trends, we might speculate that, during economically difficult times, boys may leave school earlier than girls do because of their relatively better opportunities for cash employment.

Four countries are chosen here to illustrate patterns of educational differentials by sex in detail: two in East Africa (Kenya and Tanzania) and two in West Africa (Côte d'Ivoire and Senegal). In Côte d'Ivoire and Senegal, a gender gap of 20 points and 10 points, respectively, has been sustained in the percentage with at least four years of schooling (see Figure 7), although both boys and girls stand at well below the 75 percent mark in both countries. Interestingly, the gap is larger in Côte d'Ivoire even though the country's overall levels are higher and the proportion of its government expenditures for primary education is greater than is the case in Senegal. Recent points of observation indicate that, in both countries, girls continue a slow trend upward for this measure. In Côte d'Ivoire, however, boys have reached a plateau, and in Senegal the percentage of 15-19-year-old boys completing at least four years of school has declined slightly to just over 45 percent. In East Africa, both Kenya and Tanzania show striking trends towards gender equity, and both countries have achieved relatively high levels of fouryear completion (75 percent or greater), even though Tanzania is far poorer than Kenya and has endured greater economic hardship. Although girls in both countries continue to make small gains in completing four years of schooling, small declines are found for boys since the mid-1980s.

Disparities in educational patterns and trends across urban and rural sectors are also revealing of a government's commitment to or capacity for providing schooling for its population. ${ }^{26}$ Although the majority of the population in all countries under review still live in rural areas (as shown in Table 1), all have become more urban over time, and 


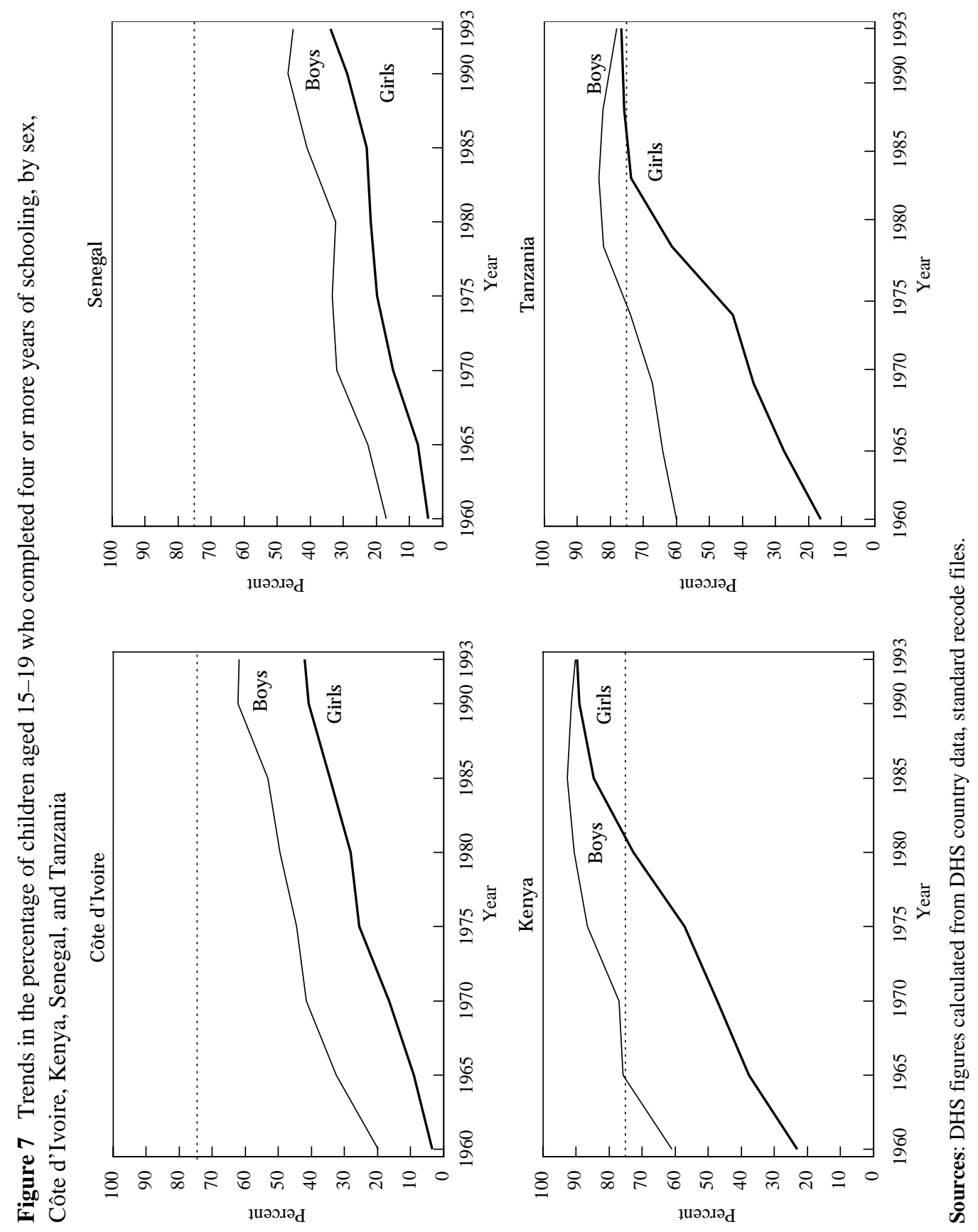


in six of them, Botswana, Cameroon, Côte d'Ivoire, Senegal, South Africa, and Zambia, at least 40 percent of the population was living in urban areas by 1990 . Trends in ruralurban educational attainment are illustrated in Figure 8. Analogous to Figure 6, this figure provides ratios of the percentage of rural to urban children completing at least four years of education. A ratio of one indicates equity between rural and urban populations, and ratios below one indicate that the percentage of rural 15-19-year-olds who have completed four years of schooling is less than that for those living in urban areas. Urban and rural divisions are based on current residence. To the extent that the more educated rural dwellers tend to migrate to urban areas over time, the measure increasingly will understate educational levels for rural areas at successively earlier dates in the past and depress the value of the ratio (assuming the additional migrants to the urban areas do not have a substantial impact on urban educational estimates). As in the analysis of gender gaps, one measure - those completing at least four years of school-is chosen for a few select countries, but the patterns of ratios are similar for the other measures of education.

In no country has the gap between rural and urban areas been fully closed. Moreover, the gains shown for narrowing rural to urban disparities do not appear to be as impressive as the gains for narrowing differences in education by sex. Some countries, typified by Mali on the graph, appear to have made no progress at all since about 1975 (Burkina Faso and Senegal also fit this characterization), and Malawi and Namibia show widening disparities between rural to urban levels of those completing at least four years of school. Furthermore, although most countries have made some progress in reducing rural-urban gaps, for Côte d'Ivoire, Kenya, Nigeria, and Tanzania, the trends toward unity are driven by declines in school attendance in urban areas. Kenya and South Africa are the two countries closest to achieving similar levels in rural and urban areas for children completing four years of education. In most countries, however, a substantial gap between rural and urban schooling has been sustained for three decades, regardless of level of educational attainment. The gap in most cases is exacerbated in the case of primary-school completion: Only five countries, Ghana, Kenya, Tanzania, South Africa, and Zimbabwe, have reached the 60 percent level of primary-school completion in rural areas (numbers not shown), and recent declines are threatening to remove Kenya and Tanzania from this category. 
Figure 8 Trends in the ratio of percentage of rural to urban children aged 15-19 who completed four or more years of schooling, selected countries, sub-Saharan Africa

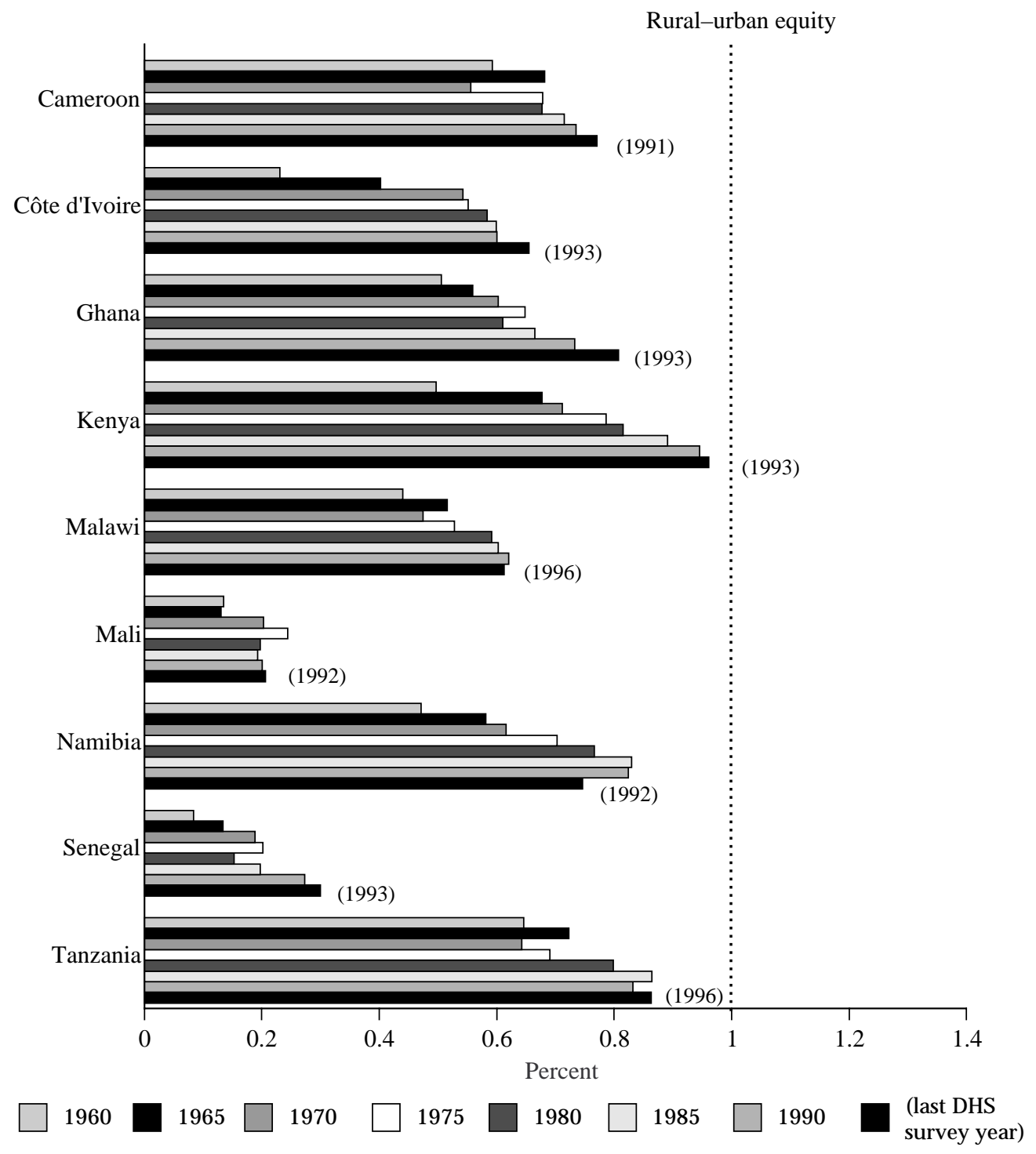

Sources: DHS figures calculated from DHS country data, standard recode files. 
This finding might suggest that access to schooling may be an important constraint in rural areas. Filmer and Pritchett (1999) have developed an ingeniously simple indicator of primary-school access in rural areas-the percentage of rich rural males aged 15-19 who have completed at least grade $1 .{ }^{27}$ Using this indicator for 13 of the 17 sub-Saharan African countries considered here, Filmer and Pritchett confirm that access in rural areas is excellent (more than 90 percent of rich rural males attend school at least through grade 1) in Cameroon, Ghana, Kenya, Malawi, Tanzania, Uganda, Zambia, and Zimbabwe, whereas attendance at this level is found to be much less satisfactory in other countries, with the access gap being most notable in Burkina Faso (60 percent), Mali (48 percent), and Senegal (42 percent).

In Figure 9, the four case-study countries are used to detail patterns of ruralurban differentials. Trends in levels of 15-19-year-olds completing at least four years of schooling are strikingly dissimilar across the four countries. Although all countries show some progress in improving these levels for both urban and rural areas, in the case of Kenya, the levels are approaching unity, whereas in Senegal, the absolute gap is widening. In Côte d'Ivoire and Tanzania, gaps of 20 and 15 percentage points, respectively, have been more or less sustained over time. Recent observations suggest a decline in rural areas in Tanzania and a slight decline in urban areas in Kenya. The figure also shows that patterns are not necessarily a function of overall level of education. Both Kenya and Tanzania have achieved fairly high levels of education, yet Kenya has succeeded in closing the rural-urban gap more than has Tanzania. The overall percentage of those completing four or more years of education is lower for Senegal than for Côte d'Ivoire (see Figure 4b). Whereas Côte d'Ivoire has managed to sustain similar increases in education in both rural and urban areas, Senegal appears to have directed the majority of educational resources to urban areas.

Even as we remain mindful of the possibility that schooling levels and trends may be slightly exaggerated, we feel confident in concluding that most countries in this review have made tremendous progress in expanding the primary education for both boys and girls. These efforts should be applauded, but not at the expense of ignoring distressing trends. The countries considered have been much less successful in ensuring that students stay in school for a minimum of four years, let alone that they complete 


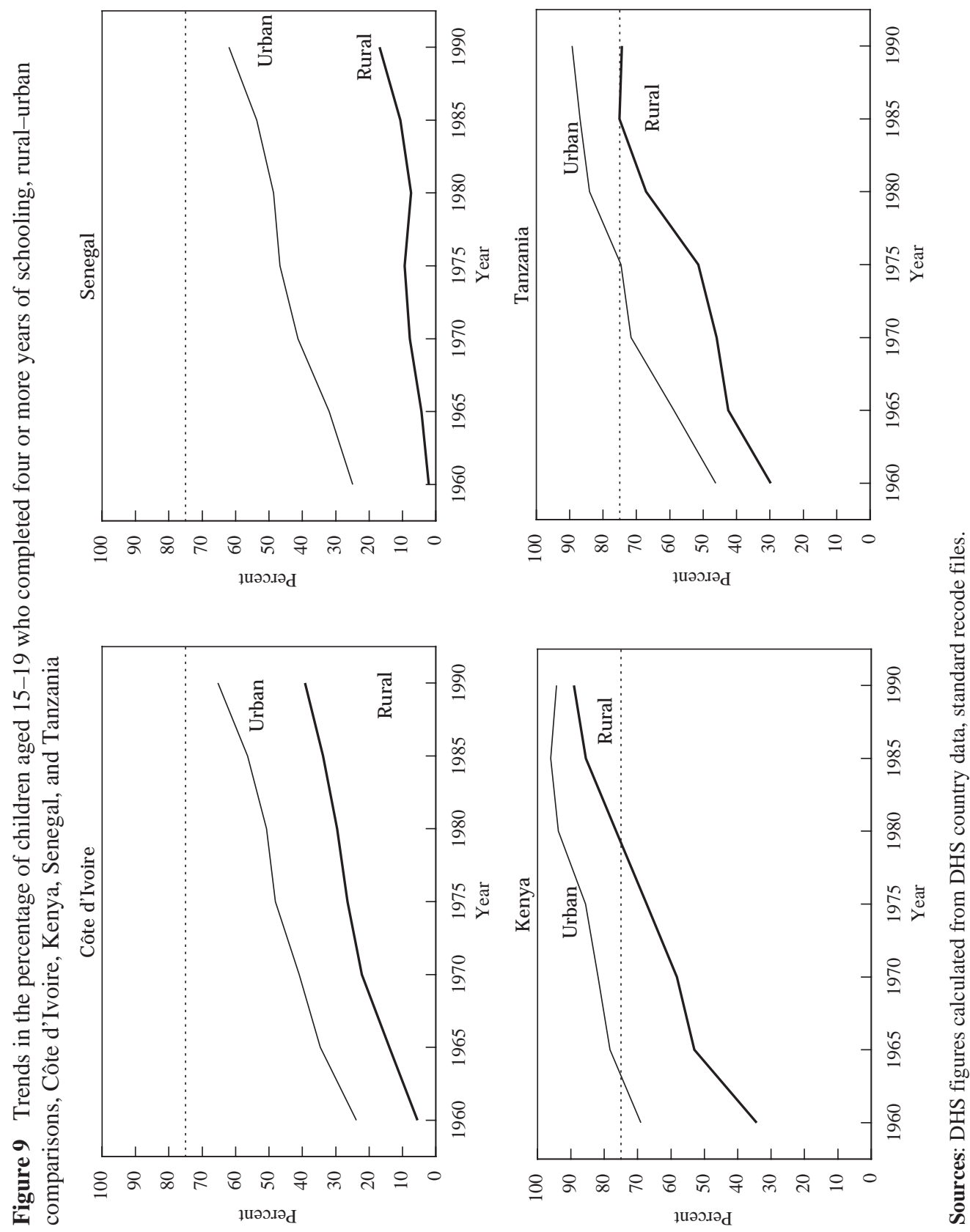


primary school, and children in rural areas appear to be substantially shortchanged educationally relative to their diverse urban counterparts. Although gaps in education for boys and girls seem to be closing, some countries are facing stagnating or declining levels of boys' educational achievement, even while girls continue to lag behind boys educationally. Most countries are far from providing mass schooling to their populations, and as a result of war, economic austerity, or high levels of population growth, some have witnessed stagnation or erosion of the educational gains of earlier decades. With a few exceptions, the picture of educational breadth and depth in the region is decidedly grim. Is there a connection between the patterns and trends of education for children and fertility trends?

\section{IMPLICATIONS OF EDUCATIONAL TRANSITIONS FOR FERTILITY CHANGE}

Although the UN projections would imply that most countries in sub-Saharan Africa have entered a fertility transition by the late 1990s (Casterline 1999), firm evidence to support many of these projections is lacking. If we rely instead on fertility estimates from censuses and surveys, particularly the recent Demographic and Health Surveys, the experience of fertility decline is apparently beginning to spread beyond many of the countries in southern Africa and Kenya, but the spread is by no means universal. In particular, evidence suggests the beginnings of a fertility transition in Botswana, Kenya, and Zimbabwe by the late 1980s, and in the case of South Africa, probably well before then (Cohen 1998; Kirk and Pillet 1998). Although another southern African country-Namibia—is likely to have embarked on a fertility transition during the 1980s as well, unfortunately data gathered at various points in time to track that transition are not yet available. Furthermore, there is now firm evidence from surveys from the mid-to-late 1990s of moderate to larger fertility declines beginning in the 1990s for Cameroon, Côte d'Ivoire, Ghana, and Senegal as well—the first countries in West Africa for which such evidence has been found (Cohen 1998; Kirk and Pillet 1998). In addition, Cohen (1998) presents evidence for small (but ambiguous) declines in overall total fertility rates for Malawi, Nigeria, Tanzania, and Zambia. ${ }^{28}$

If we assume that all countries were pretransitional in the early 1960s, we can use the percentage of decline in fertility as calculated by employing UN estimates of fertil- 
ity for 1960-65 and the most recent TFR as estimated by DHS as roughly comparable measures of the existence of a fertility decline and the extent of its progress across the 17 countries considered in this study (see Table 5). If a fertility decline of 10 percent is used as a marker of the beginning of the transition (Bongaarts and Watkins 1996), we can see that this indicator would identify as pretransitional seven of the 17 countries in this survey: Burkina Faso, Madagascar, Malawi, Mali, Nigeria, Uganda, and Zambia. If we use, instead, current contraceptive prevalence as a marker (fewer than 10 percent of

Table 5 Percentage of married women aged 15-49 currently using contraceptives and percentage decline in total fertility rate from 1960-65, by country and date of most recent survey, 17 sub-Saharan countries

\begin{tabular}{|c|c|c|c|}
\hline Country & Survey date & $\begin{array}{l}\text { Currently using } \\
\text { any contraceptive }\end{array}$ & $\begin{array}{r}\text { Percent decline in TFR } \\
1960-65 \text { to present }\end{array}$ \\
\hline Botswana & 1988 & 33 & 29 \\
\hline Burkina Faso & 1993 & 8 & 1 \\
\hline Cameroon & 1998 & 19 & 12 \\
\hline Côte d'Ivoire & 1994 & 11 & 22 \\
\hline Ghana & 1998 & 22 & 35 \\
\hline Kenya & 1998 & 39 & 42 \\
\hline Madagascar & 1997 & 19 & 8 \\
\hline Malawi & 1992 & 13 & 4 \\
\hline Mali & 1995-96 & 7 & 6 \\
\hline Namibia & 1992 & 29 & 10 \\
\hline Nigeria & 1990 & 6 & 9 \\
\hline Senegal & 1997 & 13 & 19 \\
\hline South Africa & 1987-89 & $54^{\mathrm{a}}$ & 39 \\
\hline Tanzania & 1996 & 18 & 15 \\
\hline Uganda & 1995 & 15 & 0 \\
\hline Zambia & 1996 & 26 & 8 \\
\hline Zimbabwe & 1994 & 48 & 43 \\
\hline
\end{tabular}


currently married women using a contraceptive as pretransitional), we would only include Burkina Faso, Mali, and Nigeria ${ }^{29}$ in the pretransitional category.

For the fertility transition to grow and diffuse widely throughout a population, fertility must begin to fall in rural areas. With the possible exception of South Africa, the majority of people in the sub-Saharan countries live in rural areas. Levels of urbanization vary widely, however, within sub-Saharan Africa, with levels estimated by the UN in 1990 to be greater than 40 percent in Botswana, Cameroon, Côte-d'Ivoire, Senegal, South Africa, and Zambia and less than 20 percent in Burkina Faso, Malawi, and Uganda (as shown in Table 1). Rates of urban growth also vary enormously, from the striking case of Botswana, where an almost 200 percent increase in urban residence occurred between 1980 and 1990, to the case of Ghana, where only 9 percent growth in urban areas has been seen in the last ten years. Levels and trends in urbanization matter profoundly for the fertility transition; in some cases, such as Botswana, rapid trends in urbanization may be driving the fertility transition.

Currently, among the 17 countries considered in this report, only five have achieved rural fertility rates lower than six children per woman: Botswana (5.4 in 1988), Ghana (5.4 in 1998), Kenya (5.2 in 1998), South Africa (5.0 for blacks in 1987 to 1989 [Mostert 1990]), and Zimbabwe (4.9 in 1994) (for all but South Africa, see Table 6). Among the other countries, where some evidence suggests a fertility transition, direct evidence is available from at least two independent surveys of gentle to slight declines in rural fertility in Cameroon, Côte d'Ivoire, Senegal, Tanzania, Uganda, and Zambia. These same countries, however, show greater declines in urban fertility. All countries in the sample have urban TFRs lower than six children per woman, and all but Burkina Faso, Malawi, Mali, Nigeria, Uganda, and Zambia have urban fertility rates lower than five children.

In order to explore more systematically the relationship between mass schooling and fertility change, the percentage of 15-19-year-olds completing four or more years of schooling (lagged ten years) is regressed on various markers of the fertility transition as presented in Table 5: the percentage of decline in fertility from its pretransitional base (1960-65) and the percentage of all married women (aged 15-49) currently practicing contraception (see Figures 10 and 11). ${ }^{30}$ Because Caldwell's hypothesis implies an acceleration of the decline as mass-schooling levels increase, a quadratic curve is fitted to this relationship. Both curves support the hypothesized relationships; as levels of mass 


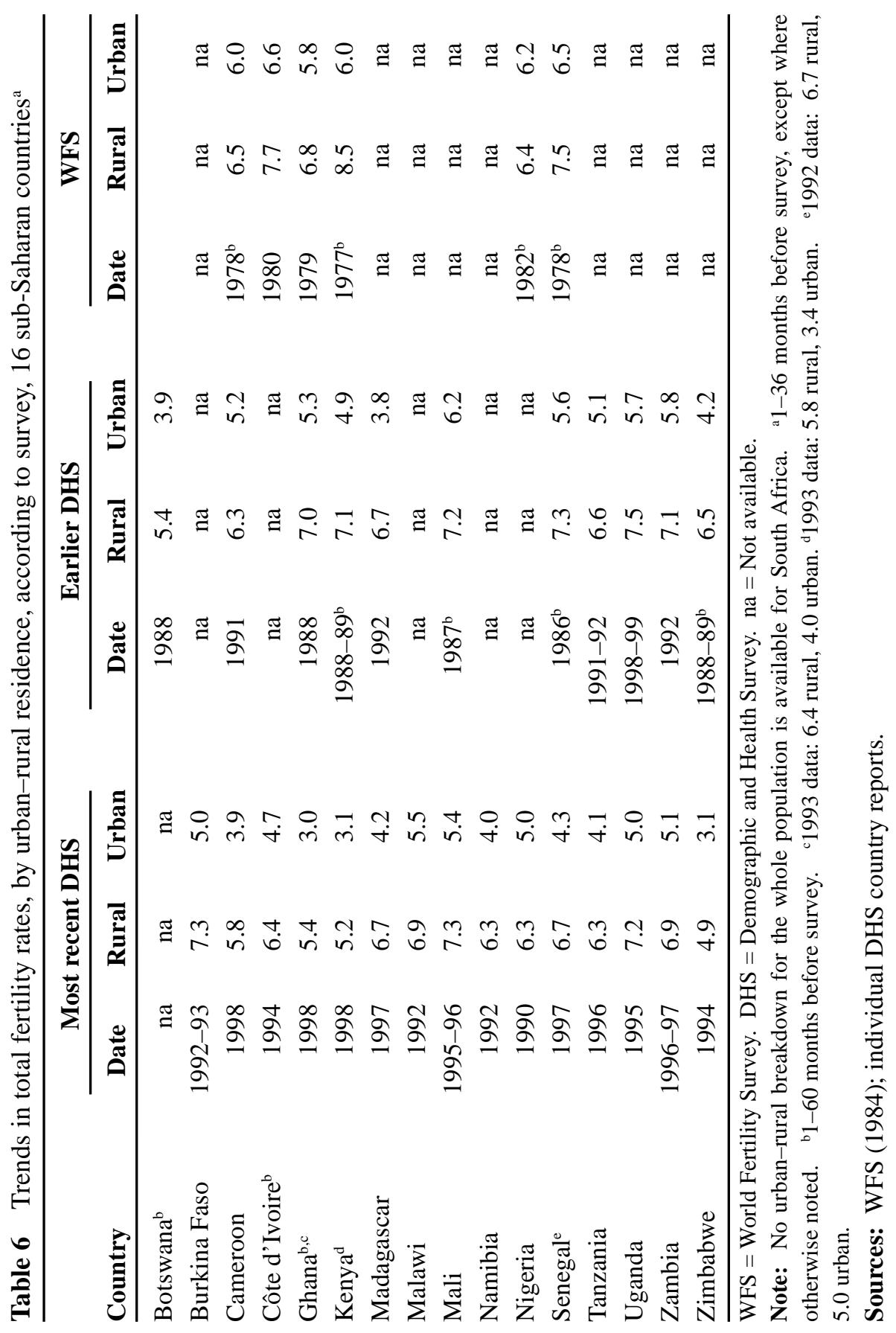




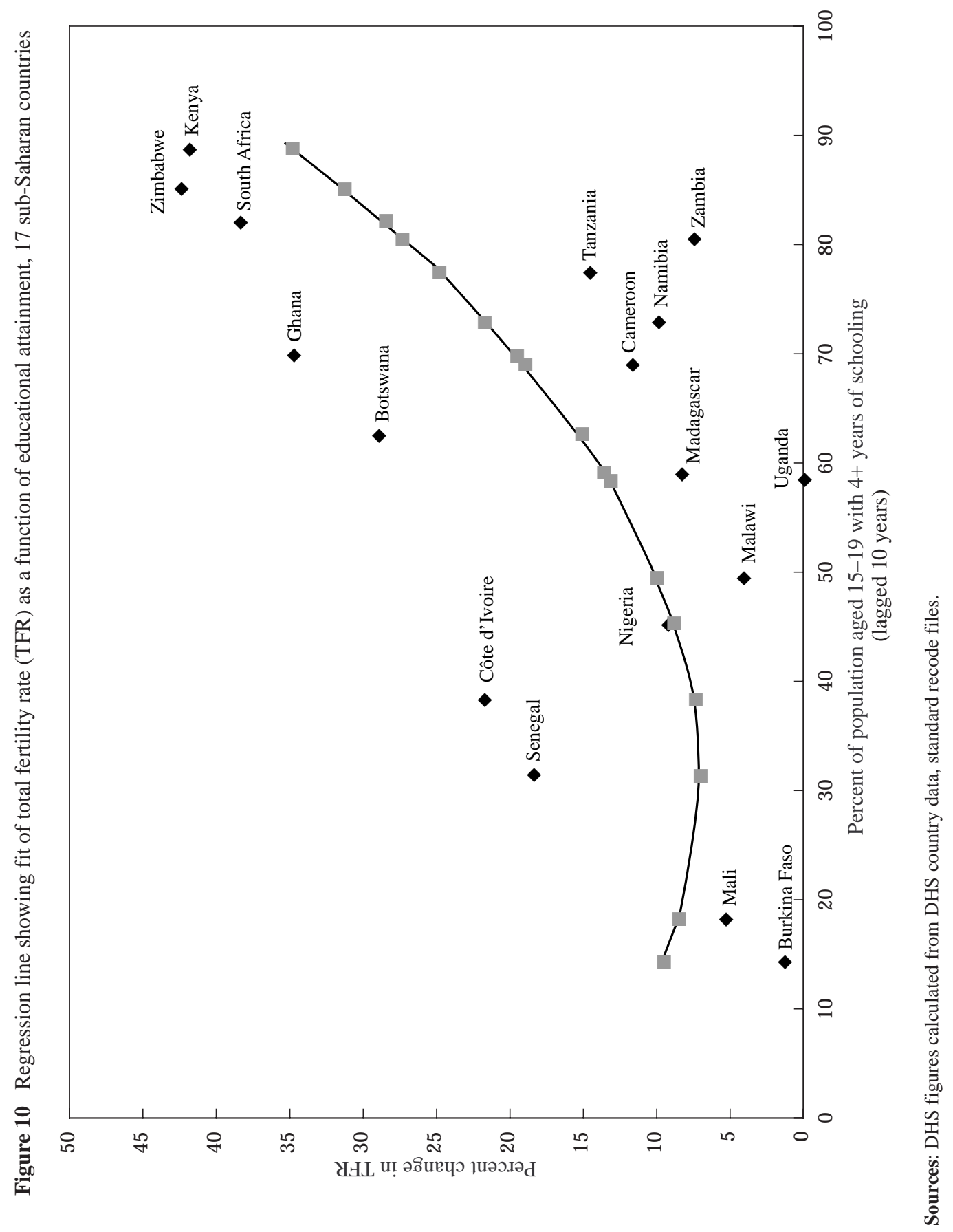




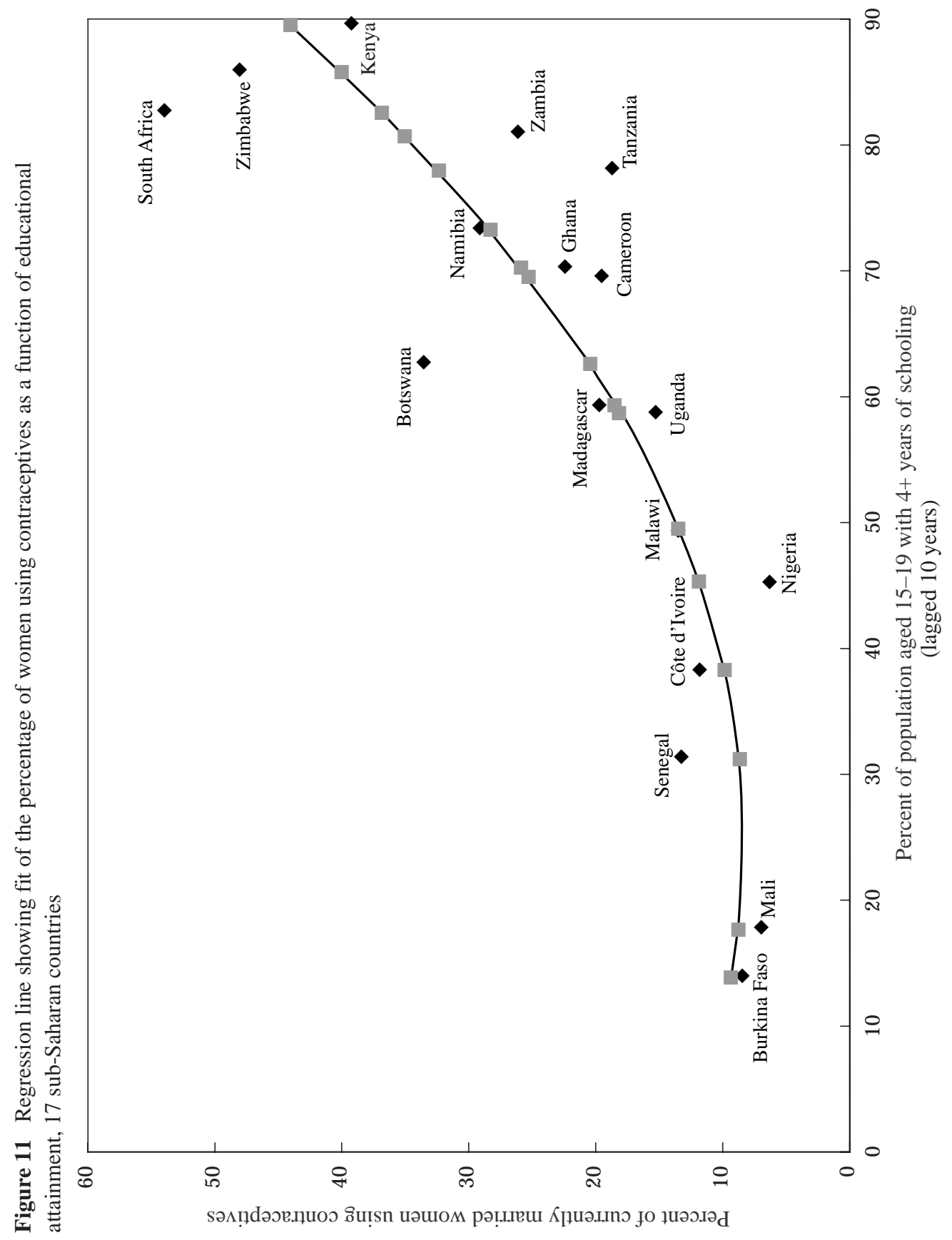


schooling increase, so do levels of fertility change and contraceptive use. The fit is much better for contraceptive use than it is for fertility, however (the adjusted R-square is 66 versus 31). This finding could reflect the contraceptive measure's being relatively free of error (the percentage of decline in TFR depends on the accuracy of two separate estimates). Furthermore, contraceptive prevalence is a fairly recent expression of the extent of deliberate fertility control.

Although we see the expected relationship between educational attainment and stage of fertility transitions, with the positive relationship between levels of education and contraceptive use becoming steeper at high levels of education, not all data points lie along the estimated line (see Figure 11). Among the countries that appear to lag in terms of contraceptive use, given their level of schooling, are Cameroon, Ghana, Nigeria, Tanzania, Uganda, and Zambia. Although we can only speculate at this point about possible reasons, we might wonder whether poor school quality and the persistence of linguistic diversity might be factors slowing the process of diffusion. Among the countries where fertility decline appears to have outstripped schooling achievements are Botswana, Senegal, South Africa, and Zimbabwe. In the cases of South Africa and Zimbabwe, near-maximum schooling levels have already been achieved. In the case of Botswana, educational attainment has risen steeply since 1977, the year represented in Figure 11. Senegal is a particularly interesting case, because it may be a precursor of future trends in which fertility declines may proceed despite the stagnation of education.

\section{CONCLUSIONS}

In most of Africa, the promise embodied in early postindependence progress of education in which the next generation of African citizens would be universally exposed to basic levels of formal schooling has yet to be realized. Countries such as Botswana, Ghana, Kenya, Namibia, South Africa, Tanzania, Zambia, and Zimbabwe are the exceptions rather than the rule, ${ }^{31}$ and most of these had achieved mass schooling by the early 1980s. Although in Cameroon, Madagascar, Malawi, and Uganda, roughly 85 percent of children have attended school, high rates of attrition prevent many of these children from attending for more than a few years; thus primary-school completion rates remain low. The rest of Africa has even farther to go to achieve mass schooling in any meaningful sense. 
Since 1980, growth rates in educational participation and attainment have slowed or halted; in some countries, these rates have even begun to decline in response to growing economic difficulties. Although a country's colonial heritage appears to have had a bearing on its initial educational investment patterns, educational participation profiles within groups of countries with common colonial roots have diverged increasingly over time. French West Africa still appears distinctive in one respect: The rural-urban gap in educational participation and attainment rates remains wide and shows few signs of narrowing.

In countries at all levels of educational participation and attainment, gender gaps are closing; in some, they have been essentially eliminated and, in a few cases, reversed (for example, in Namibia and, most recently, in Madagascar, South Africa, and Tanzania). In earlier years, this trend could be explained by relatively more rapid growth in educational participation and attainment rates for girls than for boys. More recently, this trend has been accentuated by a cessation in growth in the rates for boys and, in some countries, a decline is seen in these rates. In many cases, this closing of the gender gap is occurring at a point well below the achievement of mass schooling for either girls or boys.

In a recent article, Knodel and Jones (1996) raised questions about the current international policy emphasis on closing the gender gap in schooling when such rapid progress has already been made on this front while the gap in education between the rich and the poor remains wide and neglected. ${ }^{32}$ The data presented here appear to confirm their conclusions, at least with respect to the overall gap between rural and urban educational participation and attainment compared with the overall gap in education between boys and girls. An exploration of the interaction between gender and socioeconomic status or urban-rural residence is beyond the scope of this paper. This research would be a useful next step in assessing the full import of Knodel and Jones's argument. Moreover, not only do gender gaps in enrollment and attainment persist in the majority of sub-Saharan countries but also, when boys and girls attend school for the same number of years, their experiences may be very different. Growing evidence in the education literature suggests that discriminatory attitudes and behaviors of teachers and fellow students toward girls may have important long-term negative effects (for example, see Lloyd et al. 1998). The narrowing of the gender gap in educational attainment or enrollment tells us nothing about the degree of gender equity within schools. 
The most widely used indicator of educational progress-UNESCO's gross enrollment ratio - paints a rosy, but ultimately flawed, picture of earlier progress toward mass schooling. UNESCO's data imply that mass schooling was much more widespread by the early 1980s than, in fact, it was. Variations over time and across countries in the distribution of ages of entry into primary school and in repetition rates cause the gross enrollment ratio to be misleading as an indicator of educational progress. Although population-based schooling participation rates are preferable to UNESCO's gross enrollment ratios, African census data are not easily available for making systematic cross-country or trend comparisons. Furthermore, published census reports do not use consistent measures of educational progress, such as the proportion of students completing primary school, an inconsistency that precludes even the most basic cross-country comparisons.

The increasing availability of educational data from the DHS provided us with the opportunity to estimate comparable educational participation rates for a large number of African countries. Census/DHS comparisons for a small subset of countries for which data were available hint at the possibility that DHS samples may be slightly more educated, relative to the census, particularly in the younger ages. Thus, the current picture of educational progress in Africa based on DHS data provided in this study is likely to be a best-case scenario. This picture has implications not only for our interpretation of educational trends in Africa but also for the fertility rates derived from DHS data.

The countries in Africa that have achieved mass schooling by all three criteriaBotswana, Kenya, Namibia, South Africa, Zambia, and Zimbabwe-are also in the forefront of the fertility transition if it is measured by the percentage of married women currently using contraceptives. Cameroon, Ghana, and Tanzania have made substantial strides in education as well, although none of these countries has yet reached 90 percent enrollment overall. In these three countries, contraceptive-use rates range from 18 to 22 percent, indicating the strong beginning of a fertility transition. By way of contrast, some countries, including Côte d'Ivoire and Senegal, have not approached 90 percent attendance in primary school or 60 percent primary-school completion, and yet their estimated fertility declines appear impressive ( 22 and 19 percent, respectively). Contraceptive use in both of these countries remains relatively low, however (11 and 13 percent, respectively), suggesting that the fertility transition is beginning primarily through 
a rise in age at marriage. Furthermore, they are relatively more highly urbanized and recently both have reached mass-schooling levels in urban areas. Evidence is suggestive of rapid declines in urban fertility with much gentler declines in rural areas. The pace of the transition may depend more on the rates of urbanization in such settings than it does in others.

In light of recent setbacks in the growth of educational participation rates at primary-school levels, caused either by recent declines or by a plateauing of levels at rates that fall below mass schooling, the key question remaining is: What are the prospects for future fertility decline in a context of educational stagnation both for countries that have already begun the fertility transition and for those that have not yet begun? Once begun, are future fertility declines inevitable, even in the absence of further educational progress? Can we reasonably expect Africans to limit their fertility even if they see no prospect that their children will have a chance to complete primary school or, in some places, attend school at all? Will there be a "quantity" transition without a "quality" transition? Will the emergence of national language and culture through the influence of the mass media transform the role of education in fertility transitions as suggested by Watkins (1991)? To answer these questions, we can draw a few insights from past experience. A cautionary note is in order, however: Development has been experienced traditionally as a steady and irreversible process; contemporary African experience has no historical analog.

Although relatively few sub-Saharan countries were included in Bongaarts and Watkins's (1996) analysis of the timing and pace of the fertility transition in developing countries, they find that, for Asia, Latin America, and some of Africa, the more recent the fertility transition, the lower the level of development at the time it began, a finding that supports a hypothesis of social interaction and diffusion across borders. Although the human development index (HDI) does not contain a measure of children's schooling - it records only adult literacy_-Bongaarts and Watkins also find that the higher the level of the HDI at the beginning of the transition, the more rapid the subsequent fall in fertility. This finding might imply that although fertility transitions can begin in Africa at lower levels of development than were necessary in the past, the pace of decline will be more leisurely if mass schooling has not been achieved, because the mechanisms in place for social interaction and diffusion, including a common national language, are 
more limited. On the other hand, high rates of population growth and the youthful age structure of the population make the achievement of mass schooling in the presence of high fertility much more difficult, increasing the likelihood that fertility decline in the future will precede the achievement of mass schooling. Thus, in the future, mass schooling may be a less essential precondition for fertility decline than it has been in the past, especially as other forms of mass communication spread across the continent. However, formal schooling will surely remain an important mechanism of "demographic integration" (Watkins 1991: 45).

Caldwell's review of the historical record stressed the importance in that experience of the enforcement of compulsory schooling laws for the full attainment of mass schooling in the West. Most countries in Africa have such laws on the books. In this time of financial stringency in Africa, when the short-run prospects for further improvements in educational resources on the supply side are limited, particularly considering the continuing growth in the numbers of school-age populations, how can school enrollment and educational attainment be further increased? Parents are mostly poor, and schooling can be costly. Moreover, few African states have outreach capacity at the local level sufficient to force children to attend school. One alternative to compulsory education in a resource-thin environment is an affordable education information campaign similar to many successful family planning information campaigns launched in the past. Billboards, radio, and television could be used to inform parents of the importance of sending their children to school and of doing so at the recommended school-starting age. The campaign also could encourage parents' involvement and participation in dialogues at the community level so that school schedules could be devised that are respectful of their needs. The payoffs of such an investment could be enormous in helping fulfill national goals of basic education. Such an information program could also strengthen the positive payoffs to couples of substituting quality for quantity by reducing their family size and increasing their commitment to basic schooling for all their children.

\section{Notes}

1 This inaccessibility of data is expected to change in the near future as a result of the African census project spearheaded by Tukufu Zuberi at the University of 
Pennsylvania in collaboration with the African Population and Health Research Center (APHRC) and the census offices of many African countries.

2 The selection of countries included ten that had both DHS and comparable census data available on education with which to check data quality and coverage (Cameroon, Ghana, Kenya, Mali, Malawi, Namibia, Tanzania, Uganda, Zambia, and Zimbabwe). These choices were supplemented with countries that have populations of at least eight million (for example, Burkina Faso, Côte d'Ivoire, Madagascar, Nigeria, Senegal, and South Africa) and with countries having small populations but which also appear to have declining levels of fertility (for example, Botswana). Five countries that had no DHS data available met the size criteria for inclusion: Angola, Congo (formerly Zaire), Ethiopia, Mozambique, and South Africa. Alternative sources of data were sought for these five countries, but the search was successful only in the case of South Africa, for which we use Living Standard Measurement Survey (LSMS)-type data collected by the University of Cape Town and the World Bank in 1993 - the South African Living Standards Survey. Even though the sample of countries is dominated by those with British or French colonial traditions, it demonstrates the diversity of educational patterns in the region.

3 Axinn (1993) also explored the relationship between children's schooling and fertility in one village in Nepal. He found that whether parents sent their oldest child to school had a statistically significant effect on parents' ever use of contraceptives and on their desire for more children. He found similar results for the proportion of children sent to school. Because the study was conducted in only one village, however, it cannot be viewed as a test of Caldwell's mass-schooling hypothesis. Furthermore, in light of the endogenous nature of fertility and schooling at the household level, problems are encountered in interpreting causality.

4 This finding is based on a comparative analysis across regions, controlling for other factors including income, teachers' salaries, and population distribution.

5 This description does not treat separately the brief but important colonial German presence in what is now Namibia and Tanzania. German forms of colonial 
education were similar to the French, emphasizing a central educational policy for a very few. The Germans lost their African colonies after World War I when Tanzania became a "mandated territory" of the British and South Africa was awarded responsibility for Namibia. In Tanzania, little changed in educational policy at first, with government schools continuing operations. Over time, increased numbers of missionaries founded schools. By independence in 1961, Tanzania was still much more mixed in terms of public and religious institutions than were other British colonies (see Cameron 1970). The Namibian system eventually evolved to resemble the South African system, also with a mix of public and missionary schools until the mid-1950s, when missionary schools were taken over by the government.

6 Prior to independence, educational systems went through a number of changes and transitions that cannot be adequately addressed within the scope of this paper. See Uchendu (1979), Duffy (1961), Yansané (1985), and Cowan et al. (1965).

7 The goal of universal primary school by 1980 was proclaimed at the 1961 Conference of African States at Addis Ababa attended by African education ministers.

8 An index of ethnolinguistic fractionalization has been constructed measuring the probability that two citizens being chosen at random will come from different ethnolinguistic groups. By this measure, the average African country is two times more fractionalized than are other developing regions (Collier and Gunning 1999).

9 The development of a national curriculum was intended to create unity within the African state, overcoming the factional and centrifugal pressures of tribal, linguistic, and cultural distinctions and demands.

10 This statement is based on an assessment of the extent of educational reforms that have occurred in the sample of countries considered here, using a recent review of systems of education worldwide (Husén and Postlethwaite 1994).

11 In addition, Zimbabwe made significant investments in education after becoming independent in 1980; these investments represented 11.4 percent of its GNP in 1990. 
12 Many of the former French colonies maintained relatively high salaries for teachers, leading to higher costs per pupil (as shown in Table 2).

13 Botswana, Cameroon, and South Africa are exceptions.

14 The breakdown is not known for South Africa, because the allocation for general secondary schooling is combined with that for primary education.

15 The age range is country-specific; in each case, the lower-age boundary is the normal entrance age and the upper-age boundary is the starting age plus the number of years in the primary-school cycle.

16 Two-thirds of the weight of this component is given to literacy rates and one-third to a combined gross enrollment rating covering all three levels of schooling. The other two HDI components are longevity and real GDP per capita (in US\$ adjusted for purchasing power parity).

17 Ages 10-11 are those at which attendance rates peak in all countries, resulting from delayed ages of entry. Even in systems with no more than five grades of primary school, the assumption that all 10-11-year-olds in school are still attending primary school is reasonable.

18 The collection of African census materials from Northwestern University is compared with the census collection at the University of Texas and found to have had equal coverage of recent censuses in Africa. The collection from Northwestern University is used here.

19 In every case, the DHS survey occurred after the census. The gap in years ranged from one year for Namibia to nine years for Ghana.

20 The 1980 United Nations Principles and Recommendations for Population and Housing Censuses stated, "Educational attainment refers primarily to the highest grade completed [emphasis added] within the most advanced level attended . . " (United Nations 1980: 86). The 1998 United Nations Revision of the Principles and Recommendations for Population and Housing Censuses states unequivo- 
cally that "Educational attainment is defined as the highest grade completed within the most advanced level. ... Some countries may also [emphasis added] find it useful to present data on educational attainment in terms of highest grade attended." (United Nations 1998c: 76).

21 Thomas and Muvandi (1994) found that the 1994 Zimbabwe DHS had a slightly more educated sample of women than would have been predicted on the basis of an earlier survey, with the implication that the DHS in Zimbabwe might have drawn a sample that was slightly overeducated.

22 Barro and Lee (1996) have developed a cross-national database on the educational attainment of the adult population drawing upon census surveys and UNESCO data. Because this database is not broken down by age group, however, these data cannot be used to look at trends in enrollment and attainment by five-year cohorts.

23 In contrast to Filmer and Pritchett (1999), who grouped together those who never attended and those attended but did not complete even one grade, all those who attended school are grouped here in the "ever attended" category, even if they attended for less than a year.

24 Although some concern is expressed that the proportions completing primary school in Kenya and Zimbabwe might not be precisely estimated given discrepancies between DHS data and the most recent census, this bias is not likely to affect the conclusion given here concerning progress toward mass schooling.

25 Countries were chosen to represent various levels of education, geographic range, colonial experience, and trends in educational equity according to gender.

26 One serious problem with such a comparison is that definitions of "urban" vary by country. Most urbanites in sub-Saharan Africa live in settlements with fewer than half a million inhabitants, and a large minority live in very small settlements that are essentially rural centers. Furthermore, the extent of urban primacy, or the concentration of wealth and public resources in the largest agglomeration is more 
pronounced in sub-Saharan Africa than in any other region of the world. Thus, the category "urban" may encompass a huge range of living conditions (Brockerhoff 1999).

27 Many "rich rural males," particularly in Africa, may migrate to cities to attend school, staying with urban relatives, however, so this indicator may slightly overestimate the actual degree of access they have to schooling.

28 Moreover, Kirk and Pillet (1998) use the birth histories from the most recent DHS to demonstrate evidence of fertility decline for younger women (aged 1534) in Madagascar, Malawi, Tanzania, and Uganda.

29 The most recent national data for Nigeria are from 1990.

30 South Africa is not included in this regression. An estimate of contraceptive use is available only for the black population.

31 Ghana and Tanzania are included in this list because, although they fall below the mass-schooling threshold for basic enrollment, they surpass the threshold for 4+ and primary-school completion.

32 The existence of large gaps in educational attainment between rich and poor has been recently and systemically documented by Filmer and Pritchett (1999) using DHS data. These gaps are particularly striking in western and central Africa.

\section{References}

Ainsworth, Martha, Kathleen Beegle, and Andrew Nyamete. 1996. "The impact of women's schooling on fertility and contraceptive use: A study of fourteen subSaharan African countries." The World Bank Economic Review 10(1): 85-122.

Amin, Sajeda and Cynthia B. Lloyd. 1998. "Women's lives and rapid fertility decline: Some lessons from Bangladesh and Egypt." Policy Research Division Working Paper No. 117. New York: Population Council.

Axinn, William G. 1993. "The effects of children's schooling on fertility limitation." Population Studies 47(3): 481-493. 
Axinn, William G. and Jennifer S. Barber. 1999. "Mass education and fertility transition." Paper presented at the Annual Meeting of the Population Association of America, 25-27 March, New York.

Barro, Robert J. and Jong-Wha Lee. 1996. "International measures of schooling years and schooling quality." The American Economic Review 86(2): 218-223.

Becker, Gary S. 1991. A Treatise on the Family. Enlarged edition. Cambridge, MA: Harvard University Press.

Behrman, Jere R. and Mark R. Rosenzweig. 1994. "Caveat emptor: Cross-country data on education and the labor force." Journal of Development Economics 44 (1): 147-171.

Bledsoe, Caroline H., John B. Casterline, Jennifer A. Johnson-Kuhn, and John G. Haaga (eds.). 1999. Critical Perspectives on Schooling and Fertility in the Developing World. Washington, DC: National Academy Press.

Bongaarts, John and Susan Cotts Watkins. 1996. "Social interactions and contemporary fertility transitions." Population and Development Review 22(4): 639-682.

Brockerhoff, Martin P. 1999. Associate, Policy Research Division, Population Council, New York, personal communication.

Brass, William and Carole L. Jolly. 1993. Population Dynamics of Kenya. Washington, DC: National Academy Press.

Bureau Central des Recensements du Mali. 1991. Recensement General de la Population et de L'Habitat au Mali. Vol. 4. Bamako: Bureau Central de Recensement.

Bureau Central des Recensements et des Études de Population. 1987. Recensement General de la Population et de L'Habiter. Vol. 3. Yaounde: Government of Cameroon.

Bureau Central des Recensements et des Études de Population and Macro International. 1999. Enquête Démographique et de Santé, Cameroun, 1998. Calverton, MD: Bureau Central des Recensements and Macro International.

Bureau of Statistics of Tanzania. 1992. 1988 Population Census: National Profile of Basic Demographic and Socio-economic Characteristics. Dar es Salaam: United Republic of Tanzania.

Bureau of Statistics of Tanzania and Macro International. 1997. Tanzania Demographic 
and Health Survey. Calverton, MD: Bureau of Statistics of Tanzania and Macro International.

Caldwell, John C. 1980. "Mass education as a determinant of the timing of fertility decline." Population and Development Review 6(2): 225-255.

Casterline, John B. 1985. "Schooling and fertility: A multilevel approach.” In International Union for the Scientific Study of Population (IUSSP), International Population Conference, Florence, 1985, Vol. 2: 7-17. Liège, Belgium: IUSSP.

_ 1999. "The onset and pace of fertility transition: National patterns in the second half of the twentieth century." Policy Research Division Working Paper No. 128. New York: Population Council.

Cameron, John. 1970. The Development of Education in East Africa. New York: Teachers College Press.

Cellule de Planification et de Statistique, Direction Nationale de la Statistique, and Macro International. 1996. Enquête Démographique et de Santé, 1995-1996. Calverton, MD: Cellule de Planification et de Statistique, Direction Nationale de la Statistique, and Macro International.

Central Bureau of Statistics. 1994. Kenya Population Census, 1989. Vol. 1. Nairobi: Ministry of Planning and National Development.

Central Statistical Office of Zambia. 1995. Census and Population, Housing, and Agriculture, 1990. Vol. 10. Lusaka: Central Statistical Office of Zambia.

Central Statistical Office of Zambia, Ministry of Health, and Macro International. 1997. Zambia Demographic and Health Survey, 1996. Calverton, MD: Central Statistical Office of Zambia and Macro International.

Central Statistical Office of Zimbabwe. 1992. Census 1992: Zimbabwe National Report. Harare: Central Statistical Office of Zimbabwe.

Central Statistical Office of Zimbabwe and Macro International. 1995. Zimbabwe Demographic and Health Survey, 1994. Calverton, MD: Central Statistical Office of Zimbabwe and Macro International.

Central Statistics Office of Botswana, Family Health Division, and Institute for Re- 
source Development/Macro Systems. 1989. Botswana Family Health Survey, 1988. Columbia, MD: Central Statistics Office of Botswana and Institute for Resource Development/Macro Systems.

Central Statistics Office of Namibia. 1994. 1991 Population and Housing Census: Statistical Tables. Report B, Vol. 1. Windhoek: National Planning Commission, Republic of Namibia.

Coale, Ansley J. 1969. "The decline of fertility in Europe from the French Revolution to World War II.” In S.J. Behrman, Leslie Corsa, Jr., and Ronald Freedman (eds.), Fertility and Family Planning: A World View, pp. 3-24. Ann Arbor, MI: University of Michigan Press.

Cohen, Barney. 1998. "The emerging fertility transition in sub-Saharan Africa." World Development 26(8): 1,431-1,461.

Collier, Paul and Jan Willem Gunning. 1999. "Explaining African economic performance." Journal of Economic Literature 37(1): 64-111.

Cowan, L. Gray, David G. Scanlon, and James O’Connell. 1965. “Introduction.” In L. Gray Cowan, James O'Connell, and David G. Scanlon (eds.), Education and Nation-Building in Africa, pp. 3-42. New York: Frederick A. Praeger.

Diamond, Ian, Margaret Newby, and Sarah Varle. 1999. "Female education and fertility: Examining the links.” In Caroline H. Bledsoe, John B. Casterline, Jennifer A. Johnson-Kuhn, and John G. Haaga (eds.), Critical Perspectives on Schooling and Fertility in the Developing World, pp. 23-48. Washington, DC: National Academy Press.

Division des Statistique Démographiques and Macro International. 1997. Enquête Démographique et de Santé au Sénégal (EDS-III), 1997. Calverton, MD: Division des Statistique Démographiques and Macro International.

Donors to African Education. 1994. A Statistical Profile of Education in Sub-Saharan Africa in the 1980s. Paris. International Institute for Educational Planning.

Dow, Thomas E., Jr., Linda Archer, Shanyisa Khasiani, and John Kekovole. 1994. "Wealth flow and fertility decline in Kenya, 1981-92." Population and Development Review 20(2): 343-364. 
Duffy, James. 1961. Portuguese Africa. Cambridge, MA: Harvard University Press.

__. 1970. "Portuguese Africa: 1930 to 1960.” In Lewis H. Gann and Peter Duignan (eds.), Colonialism in Africa: 1870-1960, pp. 171-193. Cambridge, UK: Cambridge University Press.

Dubow, Saul. 1987. "Race, civilization, and culture: The elaboration of segregationist discourse in the inter-war years." In Shula Marks and Stanley Trapido (eds.), The Politics of Race, Class and Nationalism in Twentieth-Century South Africa. London: Longman Group.

Federal Office of Statistics and Institute for Resource Development/Macro International. 1992. Nigeria Demographic and Health Survey, 1990. Columbia, MD: Federal Office of Statistics and Institute for Resource Development/Macro International.

Filmer, Deon and Lant Pritchett. 1999. "The effect of household wealth on educational attainment: Evidence from 35 countries." Population and Development Review 25(1): 85-120.

Gardner, Robert. 1998. "Education.” DHS Comparative Studies No. 29. Calverton, MD: Macro International.

Ghana Statistical Service. 1984. Population Census of Ghana: Demographic and Economic Characteristics, Total Country. Accra: Ghana Statistical Service.

Ghana Statistical Service and MEASURE/DHS+. 1999. Ghana Demographic and Health Survey, 1998. Calverton, MD: Ghana Statistical Service and Macro International.

Grootaert, Christiaan. 1994. "Education, poverty, and structural change in Africa: Lessons from Côte d'Ivoire." International Journal of Educational Development 14(2): 131-142.

Guilkey, David K. and Susan Jayne. 1997. "Fertility transition in Zimbabwe: Determinants of contraceptive use and method choice." Population Studies 51(2): 173189.

Hodd, Michael. 1989. "A survey of the African economies.” In Sean Moroney (ed.), Handbooks to the Modern World: Africa, pp. 787-809. New York: Oxford University Press. 
Human Sciences Research Council. 1990. South African Demographic and Health Survey, 1987-89. Pretoria: Human Sciences Research Council.

Husén, Torsten and T. Neville Postlethwaite (eds.). 1994. The International Encyclopedia of Education. Oxford: Pergamon.

Institut National de la Statistique de Burkina Faso and Macro International. 1994. Enquête Démographique et de Santé, Burkina Faso, 1993. Calverton, MD: Institut National de la Statistique and Macro International.

Institut National de la Statistique de Côte d'Ivoire and Macro International. 1995. Enquête Démographique et de Santé, Côte d'Ivoire, 1994. Calverton, MD: Institut National de la Statistique and Macro International.

Institut National de la Statistique de Madagascar and Macro International. 1998. Enquête Démographique et de Santé, Madagascar, 1997. Calverton, MD: Institut National de la Statistique and Macro International.

Jejeebhoy, Shireen J. 1995. Women's Education, Autonomy, and Reproductive Behaviour: Experience from Developing Countries. New York: Oxford University Press.

Johansson, S. Ryan. 1991. “ 'Implicit' policy and fertility during development.” Population and Development Review 17(3): 377-414.

Kelley, Allen C. and Charles E. Nobbe. 1990. "Kenya at the demographic turning point?: Hypotheses and a proposed research agenda." World Bank Discussion Papers No. 107. Washington, DC: The World Bank.

Kelly, Michael J. 1991. Education in a Declining Economy: The Case of Zambia, 19751985. EDI Policy Case Series No. 8. Washington, DC: The World Bank.

Kinyanjui, Karbiru. 1993. "Enhancing women's participation in the science-based curriculum: The case of Kenya." In Jill Ker Conway and Susan C. Bourque (eds.), The Politics of Women's Education: Perspectives from Asia, Africa, and Latin America, pp. 133-148. Ann Arbor, MI: The University of Michigan Press.

Kirk, Dudley and Bernard Pillet. 1998. "Fertility levels, trends, and differentials in subSaharan Africa in the 1980s and 1990s." Studies in Family Planning. 29(1): 1-22.

Knodel, John and Gavin W. Jones. 1996. "Post-Cairo population policy: Does promot- 
ing girls' schooling miss the mark?" Population and Development Review 22(4): 683-702.

Lloyd, Cynthia B., Barbara S. Mensch and Wesley H. Clark. 1998. "The effects of primary school quality on the educational participation and attainment of Kenyan girls and boys." Policy Research Division Working Paper No. 116. New York: Population Council.

Marah, John K. 1989. Pan-African Education: The Last Stage of Educational Developments in Africa. Lewiston, NY: Edwin Mellen Press.

Mason, Karen Oppenheim. 1997. "Gender and demographic change: What do we know?" In Gavin W. Jones, Robert M. Douglas, John C. Caldwell, and Rennie M. D'Souza (eds.), The Continuing Demographic Transition, pp. 158-182. Oxford: Clarendon Press.

Ministry of Health and Social Services and Macro International. 1993. Namibia Demographic and Health Survey, 1992. Columbia, MD: Ministry of Health and Social Services and Macro International.

Mostert, W.P. 1990. "Recent trends in fertility in South Africa." In W.P. Mostert and J.M. Lotter (eds.), South Africa's Demographic Future, pp. 63-73. Pretoria: Human Sciences Research Council.

National Council for Population and Development, Central Bureau of Statistics, and Macro International. 1999. Kenya Demographic and Health Survey, 1998. Calverton, MD: National Council for Population and Development, Central Bureau of Statistics, and Macro International.

National Statistical Office. 1987. Malawi Population and Housing Census, 1987. Vol. 2. Lilongwe: National Statistical Office.

National Statistical Office and Macro International. 1994. Malawi Demographic and Health Survey, 1992. Calverton, MD: National Statistical Office and Macro International.

Nieuwenhuis, F.J. 1996. Development of Education Systems in Postcolonial Africa: A Study of a Selected Number of African Countries. Pretoria: Human Sciences Research Council. 
Ogbu, Osita M. and Mark Gallagher. 1991. "On public expenditures and delivery of education in sub-Saharan Africa.” Comparative Education Review 35(2): 295-318.

Pison, Gilles, Kenneth H. Hill, Barney Cohen, and Karen A. Foote (eds.). 1995. Population Dynamics of Senegal. Washington, DC: National Academy Press.

Reimers, Fernando. 1994. "Education and structural adjustment in Latin America and sub-Saharan Africa." International Journal of Educational Development 14(2): 199-129.

Robinson, Warren C. 1992. "Kenya enters the fertility transition." Population Studies 46(3): 445-457.

Rose, Pauline. 1995. "Female education and adjustment programs: A crosscountry statistical analysis." World Development 23(11): 1,931-1,949.

Rutenberg, Naomi and Ian Diamond. 1993. "Fertility in Botswana: The recent decline and future prospects." Demography 30(2): 143-157.

Scanlon, David G. 1964. "Conflicting traditions in African education." In David G. Scanlon (ed.), Traditions of African Education, pp. 1-145. New York: Bureau of Publications, Teachers College, Columbia University.

Schultz, T. Paul. 1987. "School expenditures and enrollments, 1960-80: The effects of income, prices and population growth." In D. Gale Johnson and Ronald D. Lee (eds.), Population Growth and Economic Development: Issues and Evidence, pp. 413-476. Madison: University of Wisconsin Press.

Shapiro, David. 1996. "Fertility decline in Kinshasa." Population Studies. 50(1): 89103.

South African Labour and Development Research Unit. 1993. South Africa Living Standards Survey. Cape Town: University of Cape Town and The World Bank.

Statistics Department. 1994. The 1991 Population and Housing Census (National Summary), Uganda. Entebbe: Ministry of Finance and Economic Planning.

Statistics Department and Macro International. 1996. Uganda Demographic and Health Survey, 1995. Calverton, MD: Statistics Department and Macro International.

Thomas, Duncan. 1999. "Fertility, education and resources in South Africa." In Caroline 
H. Bledsoe, John B. Casterline, Jennifer A. Johnson-Kuhn, and John G. Haaga (eds.), Critical Perspectives on Schooling and Fertility in the Developing World pp. 138-180. Washington, DC: National Academy Press.

Thomas, Duncan and John Maluccio. 1996. "Fertility, contraceptive choice and public policy in Zimbabwe." The World Bank Economic Review 10(1): 189-222.

Thomas, Duncan and Ityai Muvandi. 1994. "The demographic transition in Southern Africa: Another look at the evidence from Botswana and Zimbabwe. Demography 31(2): 185-207.

Uchendu, Victor C. 1979. "Education and the public interest: The politics of the public domain." In Victor C. Uchendu (ed.), Education and Politics in Tropical Africa pp. 280-294. Owerri: Conch Magazine.

United Nations. 1980. Principles and Recommendations for Population and Housing Censuses. Statistical Papers M(67). New York: United Nations.

—_. 1998a. World Population Prospects: The 1996 Revision. New York: United Nations.

— 1998b. World Urbanization Prospects: The 1996 Revision. New York: United Nations.

- 1998c. Principles and Recommendations for Population and Housing Censuses. Statistical Papers M(67), Revision 1. New York: United Nations.

United Nations Children's Fund (UNICEF). 1993. The Progress of Nations. New York: UNICEF.

United Nations Development Program (UNDP). 1997. Human Development Report, 1997. New York: United Nations.

United Nations Educational, Scientific, and Cultural Organization (UNESCO). 1997. Education Yearbook, 1996. Paris: UNESCO.

Van de Walle, Etienne and Andrew D. Foster. 1990. "Fertility decline in Africa: Assessments and prospects.” World Bank Technical Paper No. 125. Washington, DC: The World Bank. 
Watkins, Susan Cotts. 1991. From Provinces into Nations: Demographic Integration in Western Europe, 1870-1960. Princeton, NJ: Princeton University Press.

World Fertility Survey (WFS). 1984. Fertility in the Developing World. Voorburg, Netherlands: International Statistical Institute.

Working Group on Factors Affecting Contraceptive Use. 1993. Factors Affecting Contraceptive Use in Sub-Saharan Africa. Washington, DC: National Academy Press.

World Bank. 1988. Education in Sub-Saharan Africa: Policies for Adjustment, Revitalization, and Expansion. Washington, DC: The World Bank.

Yansané, A.Y. 1985. "The impact of France on education in West Africa.” In G. Wesley Johnson (ed.), Double Impact: France and Africa in the Age of Imperialism pp. 345-362. Westport, CT: Greenwood Press.

Yates, Barbara A. 1982. "Church, state, and education in Belgian Africa: Implications for contemporary third world women." In Gail P. Kelly and Carolyn M. Elliott (eds.), Women's Education in the Third World: Comparative Perspectives, pp. 127-151. Albany: State University of New York Press. 


\title{
POLICY RESEARCH DIVISION WORKING PAPERS
}

\author{
Recent Back Issues
}

1997

93 James F. Phillips, Fred N. Binka, Martin Adjuik, Alex Nazzar, and Kubaze Frank Adazu, "The determinants of contraceptive innovation: A case-control study of family planning acceptance in a traditional African society."

*94 John Bongaarts and Sajeda Amin, "Prospects for fertility decline and implications for population growth in South Asia."

95 Barbara S. Mensch and Cynthia B. Lloyd, "Gender differences in the schooling experiences of adolescents in low-income countries: The case of Kenya."

96 Martin Brockerhoff and Ellen Brennan, "The poverty of cities in the developing world."

*97 Carol E. Kaufman, "Reproductive control in South Africa."

*98 John Bongaarts, "Trends in unwanted childbearing in the developing world."

99 Mary Arends-Kuenning, "How do family planning workers' visits affect women's contraceptive behavior in Bangladesh?"
100 Mark R. Montgomery and Cynthia B. Lloyd, "Excess fertility, unintended births, and children's schooling."

101 Mary Arends-Kuenning, "The equity and efficiency of doorstep delivery of contraceptives in Bangladesh."

*102 Sajeda Amin, Ian Diamond, Ruchira T. Naved, and Margaret Newby, "Transition to adulthood of female factory workers: Some evidence from Bangladesh."

*103 Margaret E. Greene and Ann E. Biddlecom, "Absent and problematic men: Demographic accounts of male reproductive roles."

104 Michael P. Todaro, "Urbanization, unemployment, and migration in Africa: Theory and policy."

105 Geoffrey McNicoll, "Population and poverty: A review and restatement."

\footnotetext{
* No longer available
} 
106 Sajeda Amin and Gilda Sedgh, "Incentive schemes for school attendance in rural Bangladesh."

107 Martin Brockerhoff and Paul Hewett, "Ethnicity and child mortality in subSaharan Africa."

108 Ann E. Biddlecom and Bolaji M. Fapohunda, "Covert contraceptive use: Prevalence, motivations, and consequences."

109 John Bongaarts and Griffith Feeney, "On the quantum and tempo of fertility."

110 Barbara S. Mensch, Daniel Bagah, Wesley H. Clark, and Fred Binka, "The changing social environment for adolescents in the Kassena-Nankana District of northern Ghana: Implications for reproductive behavior."

111 Martin Brockerhoff and Ann Biddlecom, "Migration, sexual behavior, and HIV diffusion in Kenya."

112 Zeba A. Sathar and John B. Casterline, "The onset of fertility transition in Pakistan."

113 Geoffrey McNicoll, "Government and fertility in transitional and posttransitional societies."
114 John Bongaarts, "Fertility and reproductive preferences in post-transitional societies."

115 Fiona Steele, Sajeda Amin, and Ruchira T. Naved, "The impact of an integrated micro-credit program on women's empowerment and fertility behavior in rural Bangladesh."

*116 Cynthia B. Lloyd, Barbara S. Mensch, and Wesley H. Clark, "The effects of primary school quality on the educational participation and attainment of Kenyan girls and boys."

117 Sajeda Amin and Cynthia B. Lloyd, "Women's lives and rapid fertility decline: Some lessons from Bangladesh and Egypt."

118 James F. Phillips and Mian Bazle Hossain, "The impact of family planning household service delivery on women's status in Bangladesh."

119 Mark R. Montgomery and John B. Casterline, "Social networks and the diffusion of fertility control." 
120 John Bongaarts, "The fertility impact of changes in the timing of childbearing in the developing world."

121 James F. Phillips, Wendy L. Greene, and Elizabeth F. Jackson, "Lessons from community-based distribution of family planning in Africa."

122 Mark R. Montgomery, "Mortality decline and the demographic response: Toward a new agenda."

123 Mark R. Montgomery, Mary ArendsKuenning, and Cem Mete, "The quantity-quality transition in Asia."

124 Barbara S. Mensch, Wesley H. Clark, Cynthia B. Lloyd, and Annabel S. Erulkar, "Premarital sex and school dropout in Kenya: Can schools make a difference?"

125 John Bongaarts and Rodolfo A. Bulatao, "Completing the demographic transition."

126 Geoffrey McNicoll, "Population weights in the international order."

127 Cynthia B. Lloyd, Carol E. Kaufman, and Paul Hewett, "The spread of primary schooling in sub-Saharan Africa: Implications for fertility change." 